\title{
Understanding the Sahelian water budget through the isotopic composition of water vapor and precipitation
}

\author{
Camille Risi, ${ }^{1,2}$ Sandrine Bony, ${ }^{2}$ Françoise Vimeux, ${ }^{3}$ Christian Frankenberg, ${ }^{4}$ \\ David Noone, ${ }^{1}$ and John Worden ${ }^{4}$ \\ Received 28 June 2010; revised 13 September 2010; accepted 29 September 2010; published 23 December 2010.
}

[1] The goal of this paper is to investigate the added value of water isotopic measurements to estimate the relative influence of large-scale dynamics, convection, and land surface recycling on the Sahelian water budget. To this aim, we use isotope data in the lower tropospheric water vapor measured by the SCIAMACHY and TES satellite instruments and in situ precipitation data from the Global Network for Isotopes in Precipitation and collected during the African Monsoon Multidisciplinary Analysis field campaign, together with water-tagging experiments with the Laboratoire de Météorologie Dynamique general circulation model (LMDZ) fitted with isotopes. We show that some isotopic biases in LMDZ reveal the misrepresentation of dehydrating processes that would be undetected without isotopic measurements. In dry regions, the vapor isotopic composition is primarily controlled by the intensity of the air dehydration. In addition, it may also keep some memory of dehydration pathways that is erased in the humidity distribution, namely the relative contribution of dehydration in the tropical upper troposphere versus midlatitudes. In wet regions, vapor and rain isotope compositions are primarily controlled by changes in convection, through rain reevaporation and through the progressive depletion of the vapor by convective mixing along air mass trajectories. Gradients in vapor isotope composition along air mass trajectories may help estimate continental recycling intensity, provided that we could quantify the effect of convection on the isotopic composition of water vapor.

Citation: Risi, C., S. Bony, F. Vimeux, C. Frankenberg, D. Noone, and J. Worden (2010), Understanding the Sahelian water budget through the isotopic composition of water vapor and precipitation, J. Geophys. Res., 115, D24110, doi:10.1029/2010JD014690.

\section{Introduction}

[2] Understanding the water cycle in the Sahel has important societal implications given the strong variability of rainfall at the intraseasonal [Sultan et al., 2003; Matthews, 2004; Mounier and Janicot, 2004], interannual, and decadal time scales [Nicholson, 1981; Le Barbé et al., 2002] on which the local economies and societies are strongly sensitive [Sultan et al., 2005]. This variability results from complex interactions between large-scale dynamics, convective processes, and continental recycling that are difficult to disentangle [e.g., Fontaine and Janicot, 1996; Zeng et al., 1999; Nicholson, 2000; Taylor et al., 2002]. In

\footnotetext{
${ }^{1}$ Cooperative Institute for Research in Environmental Sciences, University of Colorado at Boulder, Boulder, Colorado, USA.

${ }^{2}$ Laboratoire de Météorologie Dynamique, Paris, France.

${ }^{3}$ Insitut de Recherche pour le Développement, Laboratoire HydroSciences Montpellier (UMR, CNRS, IRD, UM1, UM2) and Laboratoire des Sciences du Climat et de l'Environnement (UMR CEA-CNRS-UVSQ), Gif-sur-Yvette, France.

${ }^{4}$ Jet Propulsion Laboratory, California Institute of Technology, Pasadena, California, USA.
}

Copyright 2010 by the American Geophysical Union. 0148-0227/10/2010JD014690 addition, the loss of infrared energy to space, and thereby the Earth's greenhouse effect, is very sensitive to humidity variations in the driest regions of the tropics [Spencer and Braswell, 1997]. Understanding the processes that control humidity over the Sahel and the nearby Sahara is thus important to understand what controls the magnitude of the water vapor feedback.

[3] Water vapor isotopologues $\left(\mathrm{H}_{2}^{16} \mathrm{O}, \mathrm{HDO}, \mathrm{H}_{2}^{18} \mathrm{O}\right)$ fractionate during phase changes and thus record the successive phase changes during the water cycle. With recent technological advances in isotope measurements of the tropospheric water vapor, both in situ [Gupta et al., 2009] and from space [Worden et al., 2007; Herbin et al., 2009; Frankenberg et al., 2009], water stable isotopologues are increasingly cited as a new observational tool to better understand and quantify processes controlling atmospheric humidity [Worden et al., 2007; Frankenberg et al., 2009; Sherwood et al., 2010a; Galewsky and Hurley, 2010], estimate water budgets at the continental scale [Gat and Matsui, 1991; Brown et al., 2008], and better constrain convective parameterizations [Bony et al., 2008; Lee et al., 2009].

[4] In this study, we show how the water isotopic composition can help analyze the different components of the 
Sahelian water cycle, and, more generally, we examine what information may be inferred from space-borne or in situ isotope measurements. The Sahel benefits from the large amount of data collected as part of the African Monsoon Multidisciplinary Analysis (AMMA) campaign [Janicot et al., 2008; Redelsperger et al., 2006], including precipitation sampling for isotopic analysis [Risi et al., 2008b, 2010a]. Further, the Sahel and Sahara are the regions where isotope measurements by the satellite instrument SCIAMACHY are the most frequent and accurate [Frankenberg et al., 2009], providing the only isotope measurement in the lower troposphere to date with such a good temporal and spatial coverage. The isotope composition of the lower troposphere vapor is key to understand the composition of the precipitation, since the boundary layer vapor feeds convective systems and interacts isotopically by diffusive exchanges with the subsequent precipitation [Lawrence et al., 2004; Risi et al., 2008a, 2008b, 2010a]. Moreover, it allows us to investigate the continuous evolution of isotopes as a response to atmospheric processes and to document the isotopic variability even in dry regions where it does not rain.

[5] A first step to assess what we can learn from water isotopic measurements is to better understand what controls the isotopic variations in vapor and precipitation at the seasonal and intraseasonal time scales. We expect the isotope composition of vapor and precipitation to be affected by a variety of processes including large-scale subsidence [Frankenberg et al., 2009], dehydration history [Galewsky et al., 2007; Galewsky and Hurley, 2010], convective mixing by unsaturated downdrafts [Risi et al., 2008a, 2010a], condensate and precipitation evaporation [Risi et al., 2008a; Wright et al., 2009], isotopic exchanges between rain and water vapor [Lawrence and Gedzelman, 1996; Lawrence et al., 2004; Worden et al., 2007; Field et al., 2010] and continental recycling [Gat and Matsui, 1991; Brown et al., 2008]. To disentangle these different effects, we use a general circulation model (GCM) fitted with water isotopologues (Laboratoire de Météorologie Dynamique (LMDZ), LMDZiso; Risi et al. [2010b]) in which we tag water vapor depending on its origin or the processes it undergoes. This technique, referred to as water tagging, has long been used to tag the evaporative origin of water [Joussaume et al., 1984; Koster et al., 1986, 1992; Cole et al., 1999; Delaygue et al., 2000; Werner et al., 2001; Noone and Simmonds, 2002b; Vuille et al., 2003; Yoshimura et al., 2004; Frankenberg et al., 2009]. In this study we further exploit this tool to tag the temperature at which water vapor has undergone its last condensation and water vapor that has transited through convective downdrafts or through microphysical processes that affect the atmospheric moistening.

[6] Our ultimate goal is to design quantitative isotopic diagnostics to understand and estimate the relative contributions of large-scale dynamics, convection, and land surface recycling on the moisture budget of the Sahel and its variability and to evaluate its representation in climate models. Achieving such an ambitious goal is beyond the scope of any single paper. Nonetheless, this paper explains how these processes are imprinted in the precipitation and vapor isotopic composition using a novel water-tagging methodology. In turn, our improved understanding of the isotopic controls will allow us to improve our understanding of the water cycle over the Sahel.
[7] In section 2, we present the observational data sets used in this study and the LMDZ-iso GCM, which we evaluate in section 3 . In section 4 , we use the water-tagging experiments with LMDZ-iso to investigate isotopic controls and discuss the implications for inferring water budgets. Finally, we conclude and present perspectives for future work in section 5 .

\section{Data and Model}

\subsection{Data}

\subsubsection{Isotopic Data Collected During the AMMA Campaign}

[8] During the intensive period of the AMMA campaign [Janicot et al., 2008; Redelsperger et al., 2006], the rain was sampled after each precipitating event at three sites in the Niamey area $\left(13.53^{\circ} \mathrm{N}, 2.1^{\circ} \mathrm{E}\right)$ from June to September 2006, that is, during the entire monsoon season [Risi et al., 2008b]. Since the precipitation collected at the three sites features consistent isotope compositions, we will only discuss here the average composition of these three sites [Risi et al., 2008b].

\subsubsection{GNIP Data}

[9] Monthly isotope composition of precipitation over Western and Northern Africa are available from the Global Network for Isotopes in Precipitation (GNIP; Rozanski et al. [1993]). We use 10 stations spanning latitudes from $12^{\circ} \mathrm{N}$ to $37^{\circ} \mathrm{N}$ (Table 1), allowing us to depict zonal variations (Figure 1a).

\subsubsection{SCIAMACHY Data}

[10] The Scanning Imaging Absorption Spectrometer for Atmospheric Chartography (SCIAMACHY) instrument onboard the ENVISAT satellite measures precipitable water and $\delta D$ integrated over the entire atmospheric column [Frankenberg et al., 2009]. Therefore, it is mainly sensitive to the lower troposphere, since about $90 \%$ of the atmospheric water is found below $500 \mathrm{hPa}$. Data are available from 2003 to 2005 . Sahel locations are sampled daily at about 11:00 local time, with a footprint of about $120 \mathrm{~km}$ by $20 \mathrm{~km}$ [Frankenberg et al., 2009].

[11] In moist regions the precipitable data retrieved by SCIAMACHY features a dry bias of up to $10 \mathrm{~kg} / \mathrm{m}^{2}$ compared to European Centre for Medium-Range Weather Forecasts (ECMWF) and National Centers for Environmental Prediction (NCEP) reanalyses, possibly due to fractional cloud cover or incomplete sampling of the atmospheric column. Therefore, we discarded all retrievals associated with a cloud fraction higher than $10 \%$ or with a retrieved precipitable water differing from ECMWF reanalyses by more than $10 \%$, selecting only about one third of the measurements.

[12] We regridded the SCIAMACHY data on the same grid as LMDZ $\left(2.5^{\circ}\right.$ in latitude $\times 3.75^{\circ}$ in longitude) and sampled LMDZ-iso daily outputs coincident with observations. The accuracy of individual measurements is typically $40-100 \%$, but this uncertainty is reduced by averaging in time and space [Frankenberg et al., 2009]. On average, there are about 25 measurements per month in each grid box between $10^{\circ} \mathrm{N}-25^{\circ} \mathrm{N}$ and $10^{\circ} \mathrm{W}-30^{\circ} \mathrm{E}$ over the 3 years, leading to errors in monthly means of the order of $10-15 \%$. When analyzing the time series at the daily time scale, we restrict ourselves to the year 2005, where the sampling 


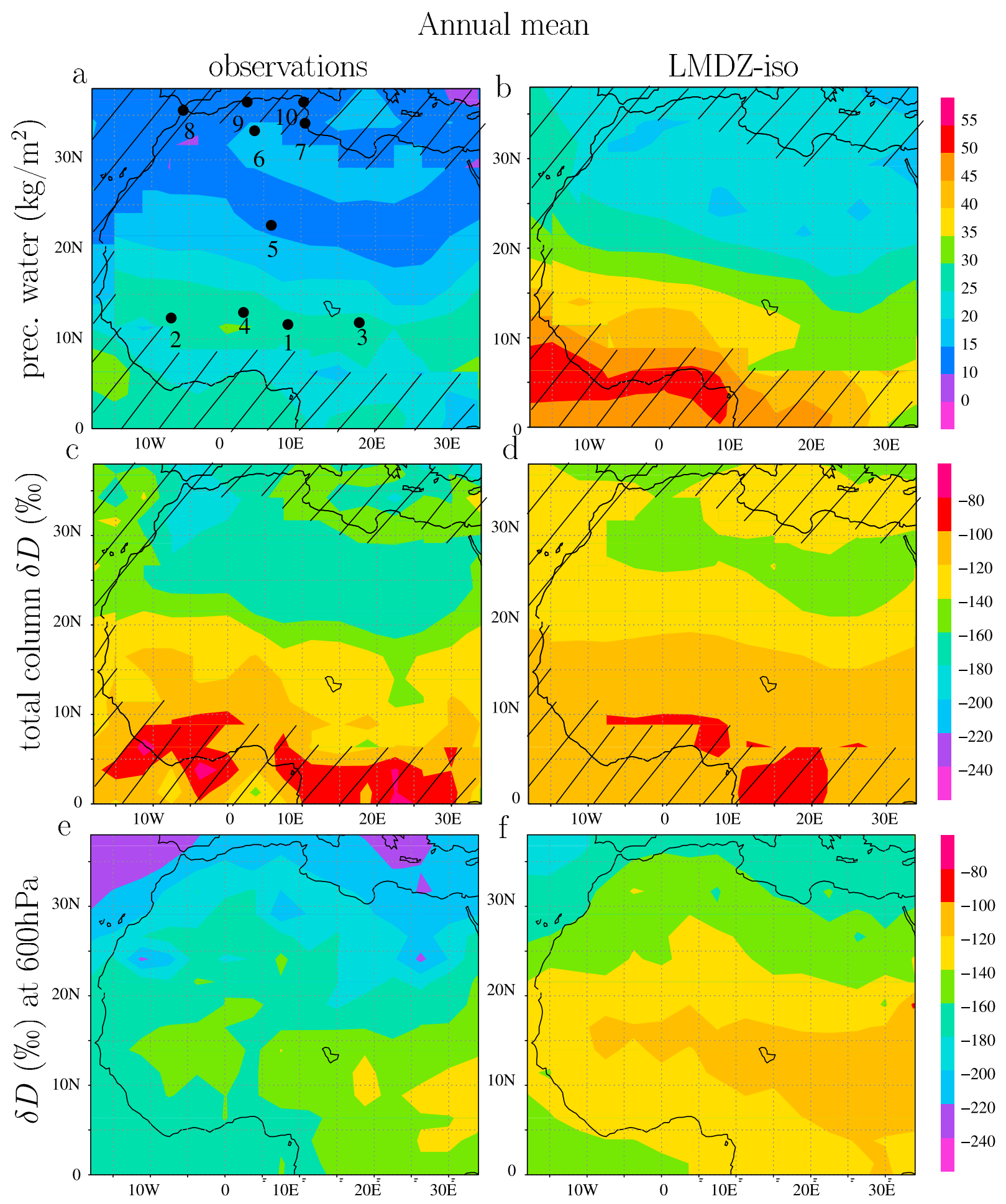

Figure 1. (a and b) Annual mean precipitable water and (c and d) total column vapor $\delta D$ observed by SCIAMACHY (Figures 1a and 1c) and simulated by LMDZ-iso (Figures $1 \mathrm{~b}$ and 1d), averaged for the years 2003-2005. Except in hatched regions, we discarded all retrievals associated with a cloud fraction higher than $10 \%$ or with a retrieved precipitable water differing from ECMWF reanalyses by more than $10 \%$. In hatched regions, no data passed this strict selection criterion: We thus relaxed it, but this hatched data should be taken with caution. Annual mean $\delta D$ at $600 \mathrm{hPa}$ (e) observed by TES and (f) simulated by LMDZ after convolution with TES kernels for the years 2004-2008. For both SCIAMACHY and TES data sets, we sampled LMDZ-iso daily outputs coincident with observations (see section 2.1 for details). GNIP stations used in this study, including Niamey where precipitation was collected during the AMMA campaign, are shown in Figure 1a: 1, Kano; 2, Bamako; 3, N'Djamena; 4, Niamey; 5, Assekrem; 6, Fes; 7, Sfax; 8, Gibraltar; 9, Algiers; 10, Tunis. 
Table 1. Coordinates and Time Period of Activity for the GNIP Stations Used in This Study ${ }^{a}$

\begin{tabular}{lccc}
\hline \multicolumn{1}{c}{ Name } & Latitude & Longitude & Time Period \\
\hline Kano & $12.05^{\circ} \mathrm{N}$ & $8.53^{\circ} \mathrm{E}$ & $1961-1973$ \\
Bamako & $12.32^{\circ} \mathrm{N}$ & $7.57^{\circ} \mathrm{W}$ & $1962-1998$ \\
N'Djamena & $12.13^{\circ} \mathrm{N}$ & $15.03^{\circ} \mathrm{E}$ & $1964-1995$ \\
Niamey & $13.52^{\circ} \mathrm{N}$ & $2.09^{\circ} \mathrm{E}$ & $1992-1999$ \\
Assekrem & $23.27^{\circ} \mathrm{N}$ & $5.6^{\circ} \mathrm{E}$ & $1993-2001$ \\
Fes & $33.58^{\circ} \mathrm{N}$ & $4.59^{\circ} \mathrm{W}$ & $1994-2001$ \\
Sfax & $34.43^{\circ} \mathrm{N}$ & $10.41^{\circ} \mathrm{E}$ & $1992-2001$ \\
Gibraltar & $36.15^{\circ} \mathrm{N}$ & $5.35^{\circ} \mathrm{W}$ & $1962-2001$ \\
Algiers & $36.78^{\circ} \mathrm{N}$ & $3.05^{\circ} \mathrm{E}$ & $1998-2001$ \\
Tunis & $36.83^{\circ} \mathrm{N}$ & $10.23^{\circ} \mathrm{E}$ & $1968-2001$ \\
\hline
\end{tabular}

${ }^{\mathrm{a}} \mathrm{By}$ comparison, the time periods for SCIAMACHY and TES are 20032005 and 2004-2008, respectively.

frequency over West Africa is much larger than for the two other years.

\subsubsection{TES Data}

[13] To check the robustness of some results found with the SCIAMACHY data set, we compared with monthly seasonal cycles in $\delta D$ retrieved by the Tropospheric Emission Spectrometer (TES) instrument [Worden et al., 2006, 2007] onboard the Aura satellite. We used measurements over the 2004-2008 period. We selected only retrievals for which the degree of freedom was higher than 0.5 to ensure a significant sensitivity to the true state [Worden et al., 2006; Lee et al., 2009]. We corrected the HDO data for a 5\% bias [Worden et al., 2006] depending on the averaging kernels. We sampled LMDZ-iso daily outputs coincident with observations and convolved them with monthly mean TES averaging kernels and a priori constraint [Worden et al., 2006]. We analyze results at $600 \mathrm{hPa}$ where the instrument sensitivity is maximum.

\subsubsection{Relative Humidity and Precipitation Data}

[14] To evaluate the relative humidity $(\mathrm{RH})$ simulated by LMDZ during the 2003-2005 period over which the SCIAMACHY data are available, we use NCEP reanalyses [Kalnay et al., 1996]. We checked the realism of the NCEP reanalyses using four-times-daily radiosonde measurements collected as part of the AMMA campaign [Nuret et al., $2008]$ in 2006 in Niamey, Agadez (Niger, $16.97^{\circ} \mathrm{N}, 7.99^{\circ} \mathrm{E}$ ) and Tamanrasset (Algeria, $22.79^{\circ} \mathrm{N}, 5.52^{\circ} \mathrm{E}$ ). NCEP profiles for the same year are always within $10 \%$ of the radiosonde data at levels up to $700 \mathrm{hPa}$, with a slight moist bias (up to $10 \%$ ) in summer and a slight dry bias (up to $5 \%$ in RH units) in winter at low levels. The daily variability is well captured especially in winter (over Niamey at $700 \mathrm{hPa}$, correlations in DJF and JJA are 0.94 and 0.52 , respectively). Therefore, we use the NCEP data for RH.

[15] We use the Global Precipitation Climatology Project (GPCP; Huffman et al. [1997]) as the precipitation data set, which agree very well with other precipitation data sets (CMAP [Xie and Arkin, 1997] or CRU [New et al., 1999] over this region [Cook and Vizy, 2006].

\subsection{Model}

[16] LMDZ4 [Hourdin et al., 2006] is the atmospheric component of the IPSL-CM4 ocean-atmosphere coupled model [Marti et al., 2005] used in CMIP3 [Meehl et al.,
2007]. It is used with a resolution of $2.5^{\circ}$ in latitude, $3.75^{\circ}$ in longitude, and 19 vertical levels. The physical package includes the Emanuel convective scheme, representing explicitly an unsaturated downdraft driven by rain reevaporation [Emanuel, 1991; Emanuel and ZivkovicRothman, 1999]. The boundary layer is treated by a simple diffusive scheme. In our control simulation, advection is a simple upstream scheme [Godunov, 1959].

[17] The isotopic version of LMDZ (named LMDZ-iso) is described in detail in Risi et al. [2010b]. Isotopic processes associated with rain reevaporation, crucial in controlling the precipitation composition [Lee and Fung, 2008; Bony et al., 2008; Risi et al., 2010b], are represented in detail [Bony et al., 2008].

[18] LMDZ is forced by observed sea surface temperatures following the AMIP protocol [Gates, 1992]. To facilitate the comparison between GCM simulations and observations on a daily basis, horizontal winds at each vertical level are nudged by NCEP reanalyses [Kalnay et al., 1996]. The simulation is the same as the nudged simulation described in Risi et al. [2010b], except that we use NCEP rather than ECMWF [Uppala et al., 2005]. Indeed, due to a southward bias of the Inter-Tropical Convergence Zone (ITCZ) in West Africa in ECMWF reanalyses, LMDZ underestimates the total monsoon precipitation over Niamey from June to September by a factor of 4 compared to GPCP when nudged by ECMWF. Our simulation starts in 2002 from a simulation nudged by ECMWF starting in 1977, so the water isotopic composition is already at equilibrium during the 2003-2006 period that we analyze.

[19] Following this setup, we performed several sensitivity tests that will be detailed when relevant. The land surface scheme in LMDZ is a simple bucket in which no distinction is made between bare soil evaporation and transpiration and no fractionation is considered during evapotranspiration [Hoffmann et al., 1998; Noone and Simmonds, 2002a; Risi et al., 2010b]. Therefore, in sensitivity tests to land surface conditions, LMDZ-iso was coupled with the ORCHIDEE iso land surface model [Ducoudré et al., 1993; Krinner et al., 2005] fitted with isotopes (C. Risi et al., Water stable isotopes to evaluate the hydrological budget in large-scale land surface models: Investigation with ORCHIDEE-iso, submitted to Climate Dynamics, 2010).

[20] Water-tagging experiments were performed for the 2005-2006 period. The general principle of these experiments is explained in Appendix A1 and the different experiments (Table 2), will be detailed when relevant.

\section{Evaluation of LMDZ-iso Using SCIAMACHY, GNIP, and AMMA Data Sets}

[21] Before using LMDZ-iso to investigate how atmospheric processes are imprinted in the isotopic composition of water vapor and precipitation, in this section we evaluate the ability of LMDZ-iso to simulate these compositions at the seasonal (section 3.1) and intraseasonal (section 3.2) time scales. We discuss possible reasons for some model biases that we will evidence and try to investigate to which misrepresented hydrological processes these biases reflect (section 3.3). 
Table 2. Summary of the Different Water-Tagging Experiments

\begin{tabular}{cc}
$\begin{array}{c}\text { Tagging } \\
\text { Experiment }\end{array}$ & Tag Description \\
\hline 1 & Five tags for five bins of minimum temperature undergone \\
2 & $\begin{array}{c}\text { Evaporation from land versus evaporation } \\
\text { from different oceanic basins }\end{array}$ \\
3 & Three 3-D domains representing the three main air flows \\
& in the Sahel + surface evaporation \\
4 & Unsaturated downdraft vapor versus the remaining vapor \\
5 & Precipitation reevaporation versus the remaining vapor \\
6 & Evaporation from bare soil, transpiration \\
& and oceanic evaporation \\
\hline
\end{tabular}

\subsection{Evaluation at the Seasonal Time Scale}

\subsubsection{Vapor Composition Using SCIAMACHY Data}

[22] In the SCIAMACHY data, both the total column vapor $\delta D$ and the precipitable water are minimum over the Sahara around $25^{\circ} \mathrm{N}$ (Figures $1 \mathrm{a}$ and $1 \mathrm{c}$ ). This minimum was interpreted by Frankenberg et al. [2009] as the depleting effect large-scale subsidence in this region. North of $15^{\circ} \mathrm{N}$, corresponding to the northward extension of the monsoon flow, vapor $\delta D$ is lower in winter (Figure 2b, Figure 3), when large-scale subsidence associated with the Hadley circulation is stronger. South of $10^{\circ} \mathrm{N}$ on the other hand, vapor $\delta D$ is minimum in summer, presumably due to the depleting effect of convective activity during the monsoon season [Lawrence et al., 2004; Risi et al., 2008b]. The $10^{\circ} \mathrm{N}$ latitude constitutes a transition between these two regions, featuring a $\delta D$ minimum in winter reflecting the depleting effect of subsidence and a secondary $\delta$ minimum in summer reflecting the depleting effect of convection (Figure $3 b$ ). The TES $\delta D$ at $600 \mathrm{hPa}$ features very similar spatial and seasonal variations (Figures 1e, 1f, 2e, and 2f), increasing our confidence in the SCIAMACHY data set.

[23] LMDZ strongly overestimates the precipitable water, especially in dry regions. Such a moist bias is common in GCMs [e.g., Pierce et al., 2006; John and Soden, 2007]. LMDZ-iso simulates the $\delta D$ patterns (Figure 1d) and seasonality (Figure 2d) qualitatively well, but features two aspects of disagreement. First, the annual mean $\delta D$ is too enriched, by up to $40 \%$ o between $25^{\circ} \mathrm{N}$ and $35^{\circ} \mathrm{N}$ (Figures 1a and 1c). This enrichment bias of the model cannot be attributed to a systematic bias in the data since the model and data agree well south of $15^{\circ} \mathrm{N}$. Second, the simulated seasonality is underestimated, by up to $60 \%$ between $25^{\circ} \mathrm{N}$ and $30^{\circ} \mathrm{N}$ (Figures $1 \mathrm{~b}$ and $1 \mathrm{~d}$ ). The winter $\delta D$ is underestimated by the model by up to $80 \%$ at $30^{\circ} \mathrm{N}$ (Figures $3 \mathrm{c}$ and $3 \mathrm{~d})$. These same aspects of disagreement were already noted for iso-GSM [Frankenberg et al., 2009]. Comparing LMDZ-iso with TES supports the idea that the excessive enrichment and underestimated $\delta D$ seasonality in LMDZ is a real problem of the model and not a bias in the SCIAMACHY data set (Figures 1 and 2): on average over the Sahara region $\left(20^{\circ} \mathrm{N}-30^{\circ} \mathrm{N}\right.$ and $\left.10^{\circ} \mathrm{W}-20^{\circ} \mathrm{E}\right), \mathrm{LMDZ}$ overestimates annual mean $\delta D$ by $40 \%$ and underestimates its seasonal amplitude by $11 \%$ at $600 \mathrm{hPa}$ compared to TES.

[24] At $10^{\circ} \mathrm{N}$ in August, LMDZ-iso underestimates the convection-related depletion in August (Figure 3b). Therefore, LMDZ-iso may also underestimate the depleting effect of atmospheric convection.

\subsubsection{Precipitation Composition Using GNIP Data}

[25] Seasonal cycles of precipitation allows us to (1) check that LMDZ-iso simulates isotopic processes during rainfall, which are crucial to control the isotopic composition of the vapor [Lawrence et al., 2004; Worden et al., 2007; Field et al., 2010] and precipitation [Stewart, 1975; Risi et al., 2008a, 2008b], reasonably well and (2) provide a "ground truth" to check the robustness of the model biases evidenced when comparing to SCIAMACHY.

[26] The seasonal cycles in the vapor measured by SCIAMACHY are very similar to those measured in the precipitation at GNIP stations except for a uniform shift (Figure 3, green). This confirms that the composition of the precipitation is strongly constrained by that of the local lower tropospheric vapor [Risi et al., 2008a]. The difference between the $\delta$ in the precipitation $\left(\delta_{p}\right)$ and the vapor $\left(\delta_{v}\right)$, is well simulated by LMDZ, suggesting that LMDZ-iso represents isotopic processes during rainfall reasonably well.

[27] LMDZ-iso features the same biases for $\delta_{p}$ as for $\delta_{v}$ : north of $25^{\circ} \mathrm{N}, \mathrm{LMDZ}$ features a enrichment bias of a magnitude comparable to that in the vapor. The depletion during the monsoon season at $10^{\circ} \mathrm{N}$, likely due to the depleting effect of convection, is also underestimated. This confirms that the model biases noticed when comparing to SCIAMACHY are real and not artifact of satellite observations.

\subsection{Evaluation at the Intraseasonal Time Scale}

\subsubsection{Vapor Composition Using SCIAMACHY Data}

[28] Over Niamey, SCIAMACHY features intraseasonal modulations of vapor $\delta D$ at all seasons, with peak to peak amplitudes of about $60-80 \%$ (Figure $4 \mathrm{~b}$ ). There are two regimes for the control of $\delta D$ (Figure 5a). First, during winter, precipitable water correlates with $\delta D$ over most of West Africa and the Sahara. This suggests a control of both $\delta D$ and precipitable water by subsidence: when subsidence is stronger, the air is drier and more depleted as it comes from higher up. Second, during the monsoon season, the correlation is negative southward of $16^{\circ} \mathrm{N}$. This suggests a control by convective activity in wetter conditions during the monsoon season: convection is stronger when the air is moister, and depletes the vapor [Lawrence et al., 2004; Risi et al., 2008b]. The $16^{\circ} \mathrm{N}$ latitude coincides with the location of the intertropical discontinuity limiting the extension of the monsoon flow [Hall and Peyrillé, 2006].

[29] LMDZ-iso captures these two regimes for the control of $\delta D$ very well (Figure $5 \mathrm{~b}$ ). However, it strongly underestimates the intraseasonal variability, especially in spring and summer, with peak to peak amplitudes lower than $20 \%$ (Figure 4b).

\subsubsection{Precipitation Composition Using AMMA Data Over Niamey}

[30] Despite the nudging, LMDZ is not able to reproduce the exact phasing of the intraseasonal variability in precipitation (Figure 6a). This is expected since precipitation is affected by parameterized sub-grid-scale processes (convection, clouds) and not just constrained by the dynamics. In LMDZ, the monsoon onset occurs approximately early August compared to mid-July in the data. However, the total accumulated precipitation from 1 June to 30 September is similar (480 $\mathrm{mm}$ in GPCP and 400 in LMDZ) and the order of magnitude of the amplitude and frequency of the intraseasonal variability is correctly simulated. Even though 


\section{JJA - DJF difference}
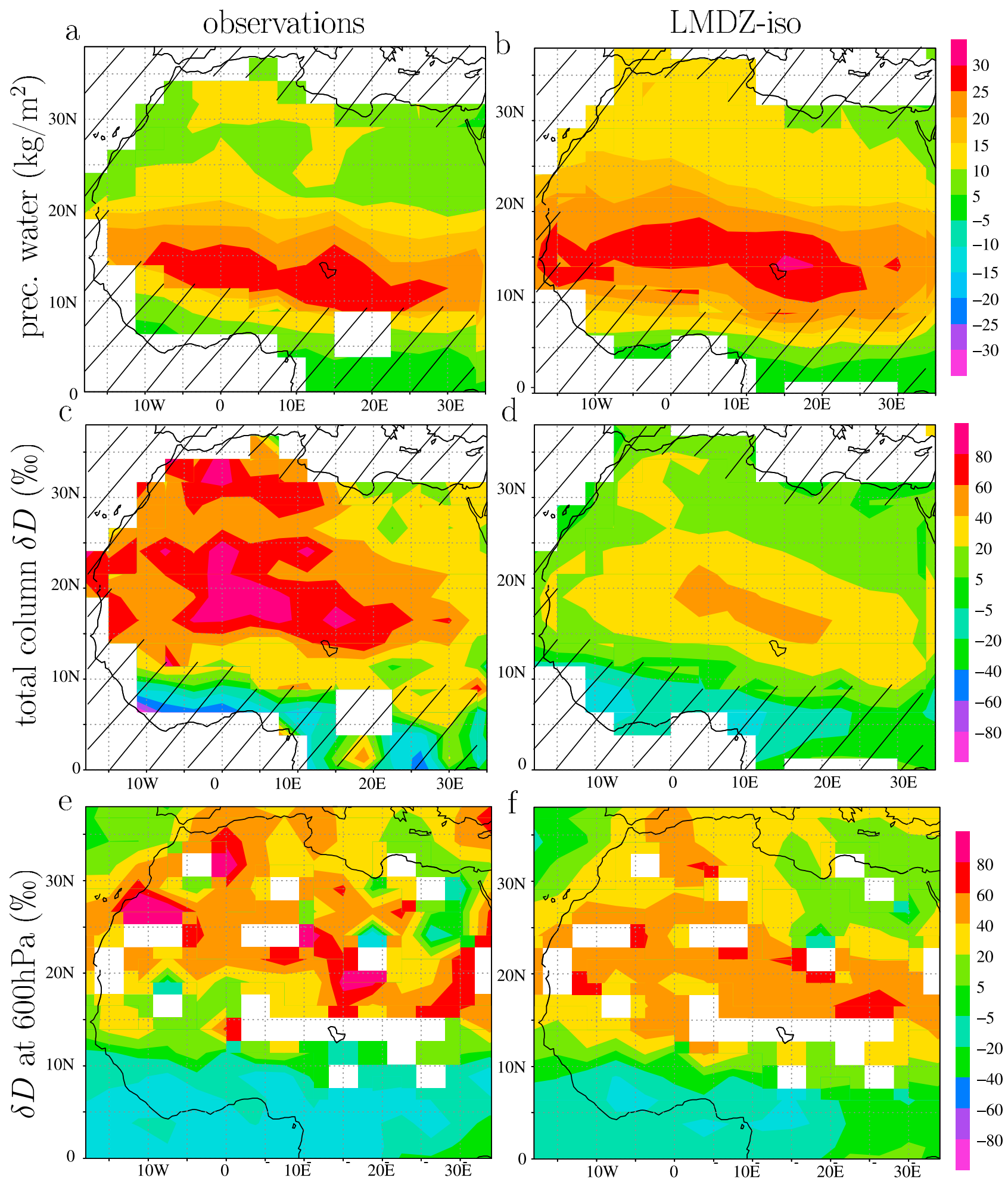

Figure 2. Same as described in the caption to Figure 1 but for JJA-DJF differences.

the simulated precipitation variability is not in phase with that observed, we show here that the main features of the response of the precipitation isotope composition to convective activity are well captured by LMDZ (Figure 6).
[31] The observed precipitation $\delta^{18} \mathrm{O}\left(\delta^{18} O_{p}\right)$ shows a strong decrease of $6 \%$ at the monsoon onset [Risi et al., 2008b], when the ITCZ abruptly shifts to a northward position from the Guinean coast to the Sahel. LMDZ-iso simulates a decrease of comparable amplitude (Figure 6b). 


\section{$\delta D(\%)$ averaged over $10^{\circ} \mathrm{W}-20^{\circ} \mathrm{E}$}
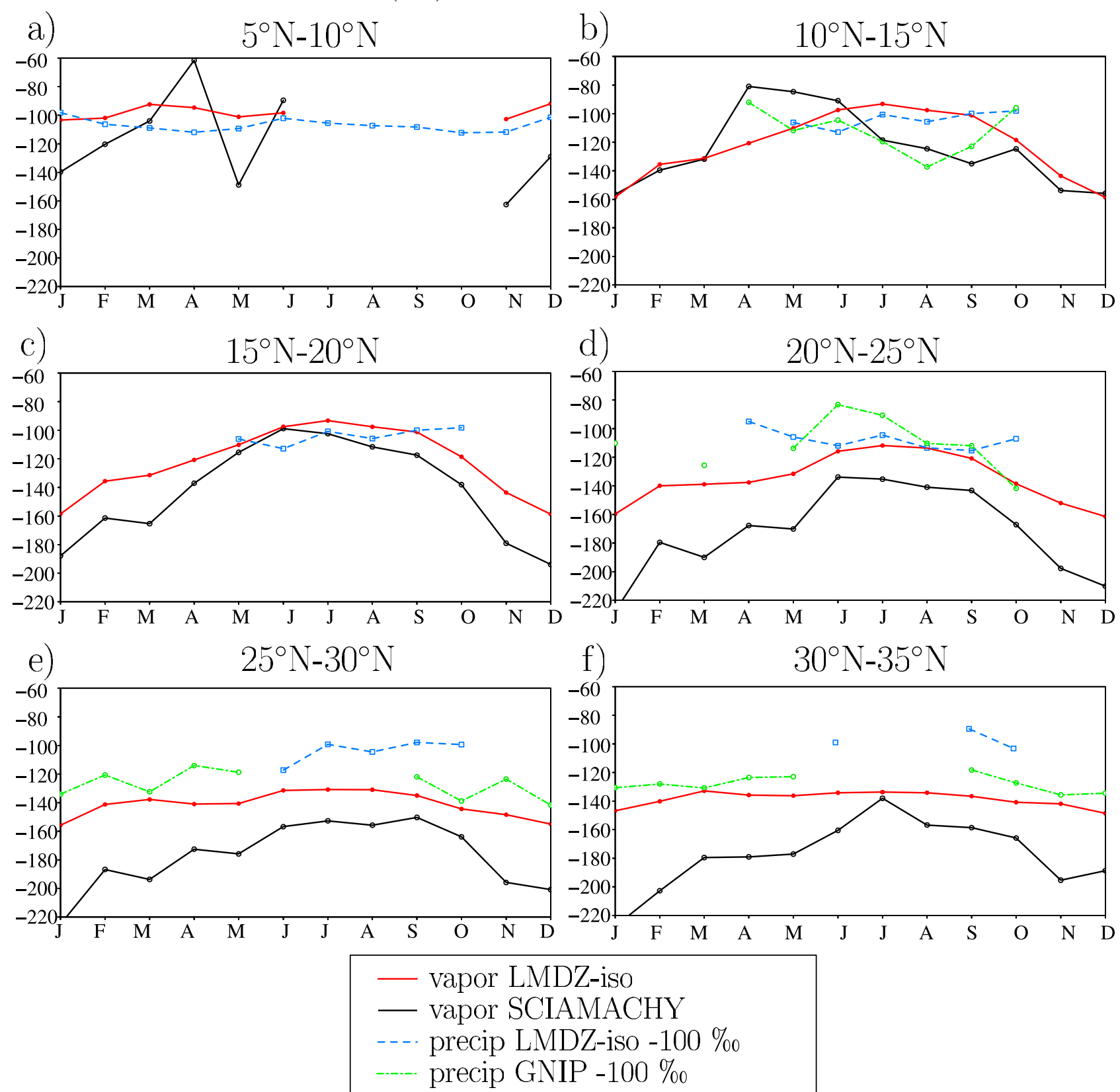

Figure 3. Seasonal cycles of column vapor $\delta D$ averaged over $2003-2005$ and over $10^{\circ} \mathrm{W}-20^{\circ} \mathrm{E}$, for SCIAMACHY (black) and LMDZ-iso (red). The different plots show values for different latitudes. Also shown is precipitation $\delta D$ simulated by LMDZ-iso (dashed blue) and observed at GNIP stations (dashed-dotted green), with $100 \%$ subtracted so that vapor and precipitation isotopic composition can be compared on the same plot.

The concomitant observed increase in deuterium excess (d-excess: $d_{p}=\delta D_{p}-8 \cdot \delta^{18} O p$ [Dansgaard, 1964]) is also well simulated (Figure 6c). LMDZ thus reproduces the isotopic signature of the monsoon onset, though slightly smoother than in observations.

[32] Before the onset, $\delta^{18} O_{p}$ variations are mostly controlled by the intensity of individual convective events, whereas after the onset, they are most correlated with convective activity averaged over the 9 previous days [Risi et al., 2008b]. These features are well reproduced by LMDZ-iso: before the onset, simulated $\delta^{18} O_{p}$ responds instantaneously to variations in convective activity $\left(\delta^{18} \mathrm{O}\right.$ increases and $d_{p}$ decreases as the daily rainfall increases; Figures $6 \mathrm{a}$ and $6 \mathrm{~b}$ ), and after the onset $\delta^{18} O_{p}$ integrates convection $\left(\delta^{18} O_{p}\right.$ best correlates with precipitation when precipitation is averaged over the 15 to 20 previous days, Figure $6 \mathrm{~d}$ ), though local controls are overestimated in the model. Therefore, LMDZ-iso can capture the time scales of the isotope response to convection. 

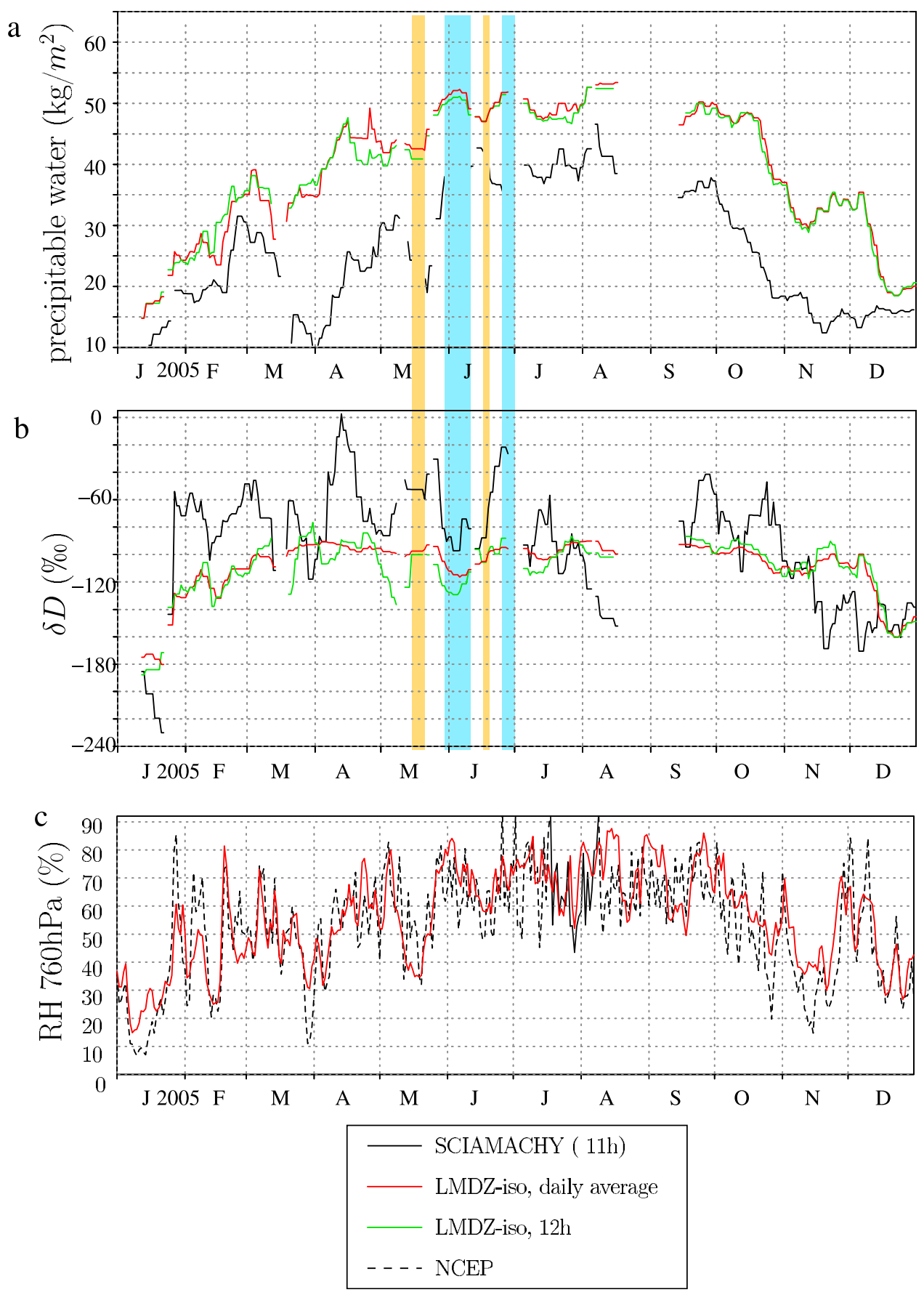

Figure 4. (a) Daily evolution of precipitable water and (b) $\delta D$ in column-integrated water vapor observed by SCIAMACHY (black) and simulated by LMDZ for daily averages (red) in 2005 in Niamey. The instant values simulated by LMDZ at 12:00 universal time coordinated (corresponding to 13:00 local time) (green). Values have been smoothed with a 5 day running mean. (c) Daily evolution of relative humidity at $760 \mathrm{hPa}$ (where $\delta D$ is the closest to the total column water $\delta D$ ) for LMDZ (red) and NCEP reanalyses (red).

\subsection{Interpretation of Simulated Isotopic Biases in Terms of Misrepresented Hydrological Processes}

3.3.1. Enrichment Bias and Underestimated Seasonality

[33] What explains the enrichment bias of the model in annual average and its underestimated $\delta D$ seasonality? In the control simulation, the enrichment bias is associated with a moist bias of about $5 \mathrm{~kg} / \mathrm{m}^{2}$ in precipitable water over the Sahara (Figure 1b). Simulated vertical velocities do not show any systematic differences from the NCEP reanalyses (as expected for a nudged simulation) suggesting that the well-simulated subsidence does not dry and deplete the air masses enough. Further, the simulated slope of $\delta D$ versus 


\section{correlation between precipitable water and $\delta D$ at the intra-seasonal scale}

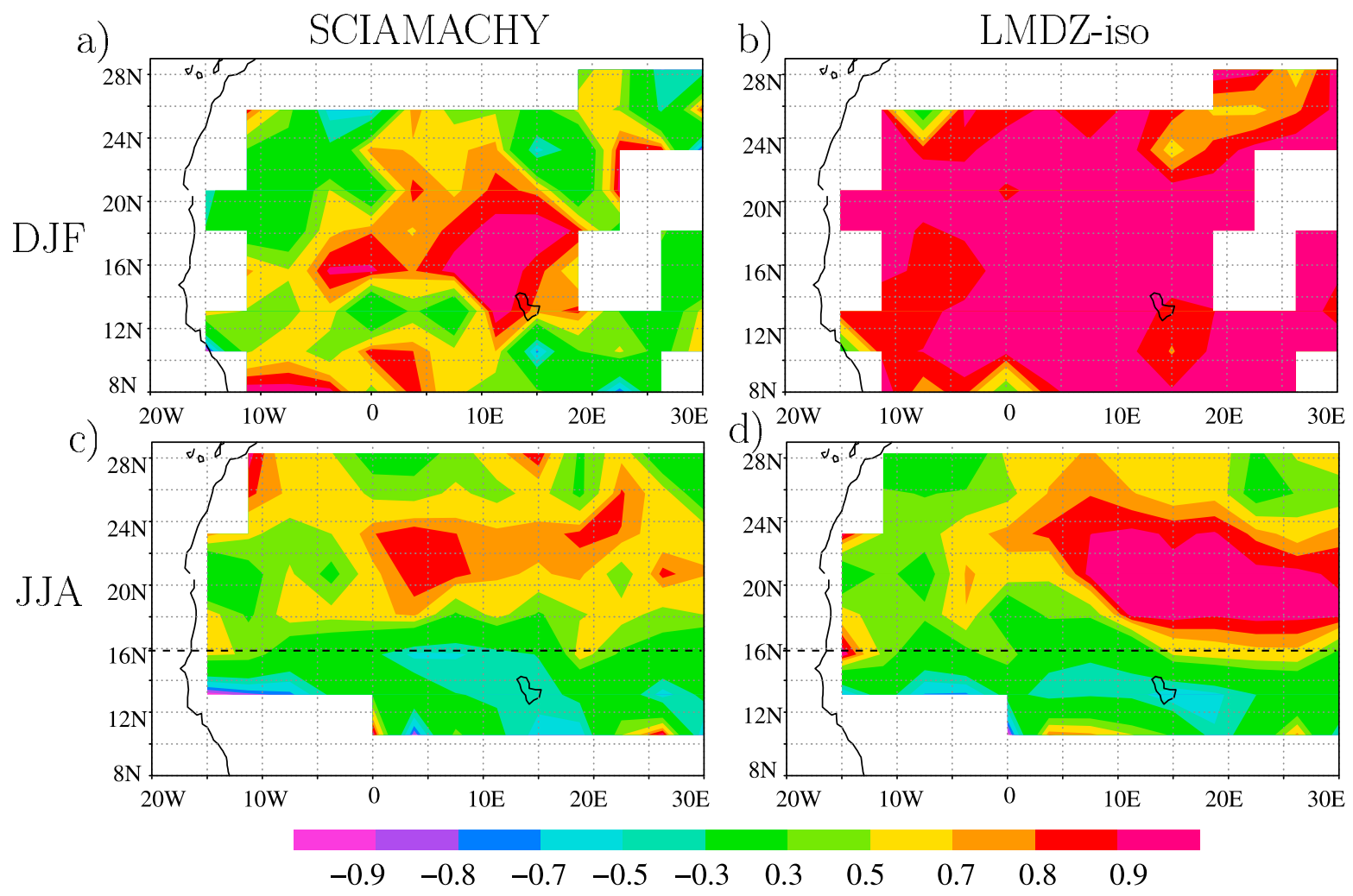

Figure 5. Correlation between precipitable water and total column vapor $\delta D$ at the intraseasonal scale during ( $a$ and b) December-January-February and (c and d) June-July-August for (a and c) SCIAMACHY and (b and d) LMDZ-iso. The time series of precipitable water and $\delta D$ over the 2003-2005 period are filtered with a running mean of 5 days, and time series filtered with a running mean of 2 months are subtracted, to focus on intraseasonal variations. The dashed line on $\mathrm{c}$ and $\mathrm{d}$ materializes the transition between subsidence-controlled and convection-controlled $\delta D$ (see text) corresponding to the northward extension of the monsoon flow.

precipitable water is strongly underestimated in the Sahara at the seasonal and spatial scales (Figure 7, green). This indicates that the underestimated depletion is due to not only the underestimated dehydrating effect of subsidence but also an underestimated depleting effect of dehydration.

[34] To explore several possibilities for the underestimated depleting effect of dehydration in LMDZ, we performed several sensitivity tests. First, in subtropical regions like the Sahel, the presence of fine filaments of moist and dry air results in very strong gradients in tropospheric RH [Emanuel and Pierrehumbert, 1996; Pierrehumbert and Roca, 1998; Roca et al., 2005], whose representation in a model requires a high resolution and accurate advection scheme [Hourdin and Armengaud, 1999]. Excessive mixing in the model may lead to the moist bias frequently seen in GCMs in the subtropics [Pierce et al., 2006; Sherwood et $a l ., 2010 \mathrm{~b}]$ and to the excessive enrichment, since mixing lines are more enriched than Rayleigh distillation lines [Dessler and Sherwood, 2003; Worden et al., 2007; Galewsky and Hurley, 2010]. To test this hypothesis, we performed three additional simulations: (1) one with a higher vertical resolution (40 levels in the vertical instead of
19); (2) one with a higher horizontal resolution, using the zoom functionality [Krinner et al., 1997] centered on West and North Africa, leading to a resolution of $60-80 \mathrm{~km}$ over the $0^{\circ}-35^{\circ} \mathrm{N}-10^{\circ} \mathrm{W}-30^{\circ} \mathrm{E}$ domain; and (3) one with a less diffusive advection scheme, using a second-order [Van Leer, 1977] rather than upstream [Godunov, 1959] advection scheme. Higher resolutions have little impact on $\mathrm{RH}$ and $\delta D$ (not shown), suggesting that the difficulty to simulate $\delta D$ is a structural problem of the model. On the other hand, with the less diffusive advection scheme, the precipitable water is strongly reduced, in much better agreement with the data (Figure 7, blue). This suggests that too strong diffusion during water vapor transport is responsible for this moist bias. However, the enrichment bias in the model remains unchanged, reflecting deeper problems in the simulation of dehydrating or remoistening processes. The fact that the vapor isotopic composition can be poorly simulated even when the precipitable water is correct highlights the interest of water vapor isotopologues to evaluate processes controlling humidity in GCMs.

[35] We thus tested the sensitivity to several dehydrating and moistening processes. First, shallow convection and 

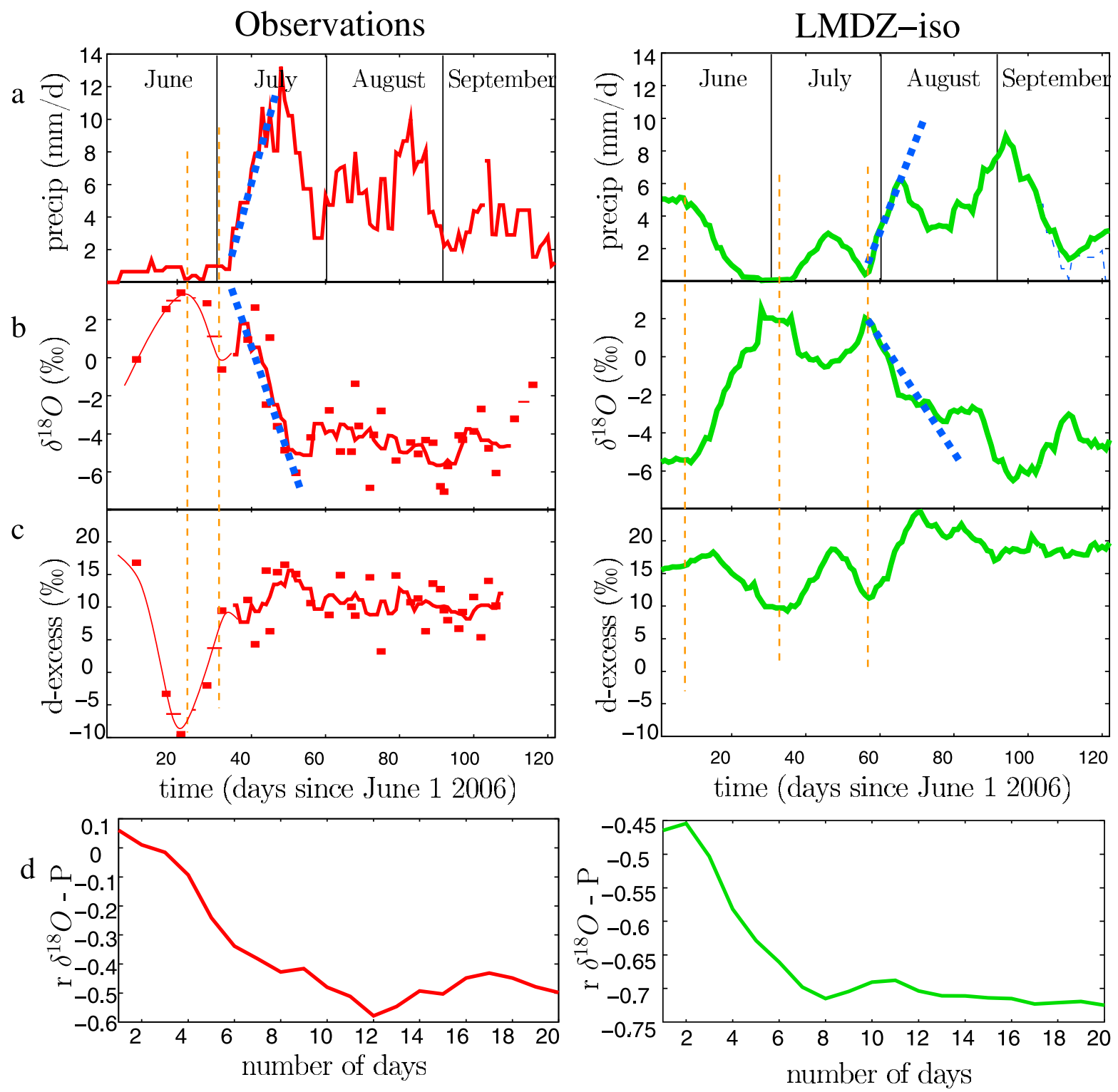

Figure 6. Comparison of the observed and simulated response of precipitation isotopes to variations in convective activity. (a) Precipitation simulated over Niamey (green) and observed by GPCP (dashed red) from June to September 2006. A 5 day running mean has been applied. (b) $\delta^{18} O_{p}$ simulated over Niamey (green) and observed (red). (c) Same as for Figure 6b but for d-excess. (d) Correlation between daily $\delta^{18} O_{p}$ and precipitation from 15 July to 30 September, as a function of the number of previous days over which precipitation rate is averaged. For the data, the GPCP precipitation is averaged over $12^{\circ} \mathrm{N}-17^{\circ} \mathrm{N}$ and $0^{\circ} \mathrm{N}-8^{\circ} \mathrm{E}$; for $\mathrm{LMDZ}$, precipitation is averaged over $8^{\circ} \mathrm{N}-13^{\circ} \mathrm{N}$ and $4^{\circ} \mathrm{W}-5^{\circ} \mathrm{E}$, where $\delta^{18} O_{p}$ is the most sensitive.

boundary layer mixing play a key role in the water and energy budgets of the Saharan atmosphere [Hall and Peyrillé, 2006; Cuesta et al., 2008], which our simple diffusive boundary layer scheme may underestimate. However, activating a mass-flux boundary layer scheme representing the vertical transport by coherent structures (i.e., thermals) within the convective boundary layer [Hourdin et al., 2002] has little impact on precipitable water and $\delta D$ (not shown). Second, the detrainment and evaporation of ice from convective systems significantly enriches the upper tropospheric water vapor [Moyer et al., 1996; Webster and Heymsfield, 2003; Wright et al., 2009], which then subsides throughout the subtropics as part of the Hadley cell. When we tune the precipitation efficiency to reduce by a factor of 10 the fraction of the condensate detrained into the environment in the upper troposphere, $\delta D$ is reduced by $200 \%$ over the tropics at $200 \mathrm{hPa}$, but is little affected in the lower troposphere (not shown). Third, in a simulation in which we coupled LMDZ to the ORCHIDEE land surface scheme, we increased the bare soil fraction by $30 \%$ to decrease the continental recycling. Although this unrealistically shuts off evapotranspiration and precipitation over the African continent, the vapor $\delta D$ is reduced by only $40 \%$ in winter, that is, half what is needed to agree with the data (not shown). 


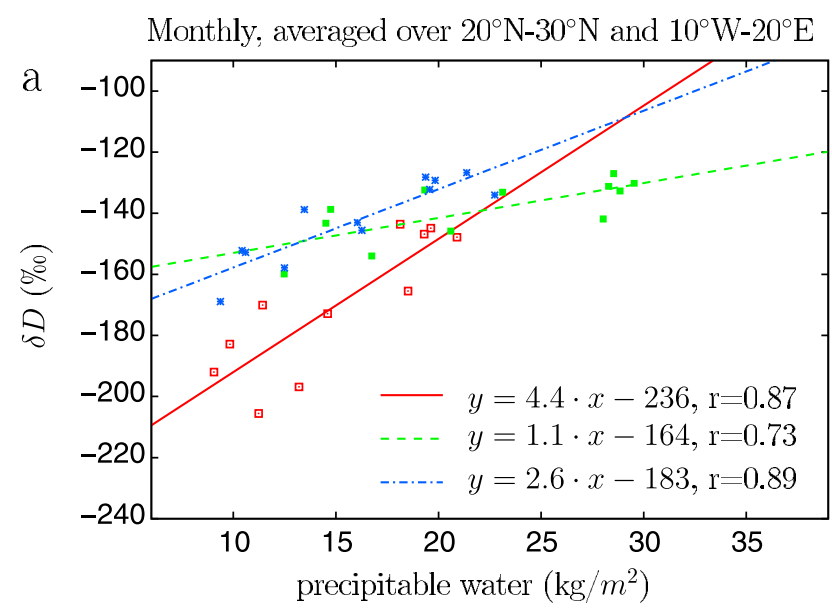

daily DJF averages, all locations in $20^{\circ} \mathrm{N}-30^{\circ} \mathrm{N}$ and $10^{\circ} \mathrm{W}-20^{\circ} \mathrm{E}$

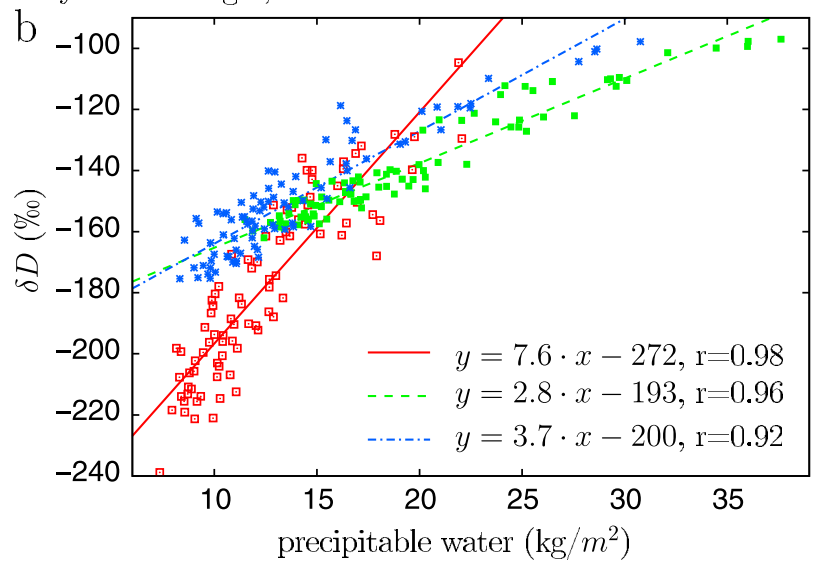

\begin{tabular}{|cl|}
\hline$\square$ & SCIAMACHY data \\
$-\cdots$ & LMDZ, standard simulation \\
$*$ & LMDZ, accurate advection scheme \\
\hline$-\cdots$ & \\
\hline
\end{tabular}

Figure 7. Total column vapor $\delta D$ as a function of precipitable water for SCIAMACHY (red empty squares), LMDZ-iso standard simulation (green full squares), and LMDZ-iso simulation with a more accurate advection scheme for water vapor (blue stars). (a) Monthly mean values averaged over $10^{\circ} \mathrm{W}-20^{\circ} \mathrm{E}$ and $20^{\circ} \mathrm{N}-30^{\circ} \mathrm{N}$. (b) Daily DJF values at all locations in the $10^{\circ} \mathrm{W}-20^{\circ} \mathrm{E} ; 20^{\circ} \mathrm{N}-30^{\circ} \mathrm{N}$ domain.

[36] To summarize these tests, the distribution of water vapor isotopic composition is extremely robust in the LMDZ-iso model. The reason for the enrichment bias in annual average and the underestimated seasonality compared to the satellite data remains unclear. Still, this study highlights isotopic biases in a GCM that are not always associated with equivalent biases in conventional variables such as RH or precipitable water. Therefore, the water isotopic composition helps identify misrepresentation of processes that would have been undetected otherwise. This added value of isotopic measurements may be explained by microphysical processes having a small influence on $\mathrm{RH}$ due to regulating processes [Sherwood and Meyer, 2006] but a larger influence on $\delta D$ [Bony et al., 2008; Wright et al., 2009].

3.3.2. Underestimated Intraseasonal Variability

[37] Despite a systematic moist bias in winter in the precipitable water, the variability in precipitable water is reasonably well captured, with intraseasonal fluctuations of the order of $10-15 \mathrm{~kg} / \mathrm{m}^{2}$ in spring and summer (Figure $4 \mathrm{a}$ ). Daily variability in $\mathrm{RH}$ in the lower troposphere is also well captured (Figure 4c), since it is strongly constrained by the large-scale circulation [Sherwood, 1996; Pierrehumbert and Roca , 1998] which we nudge in our simulations. Therefore, as was the case at the seasonal scale, the underestimated intraseasonal $\delta D$ variability may indicate misrepresentations of some processes that compensate for the water vapor distribution but not for the isotope distribution. Also, as was the case at the seasonal scale, none of the sensitivity tests lead to significant improvement of the intraseasonal variability in $\delta D$.

[38] Sampling LMDZ-iso at 12:00 local time (close to SCIAMACHY sampling at 11:00 local time) rather than using daily averages enhances the variability by a factor of about 2 (Figure 4a, green). This is because LMDZ-iso simulates a strong diurnal cycle in $\delta D$ of about $25 \%$ during moist days, with a minimum at midday, but no diurnal variations during dry days (Figure 8). This could be consistent with the isotope depletion of the vapor by vertical mixing when the boundary layer is deeper, presumably during the moister days. Therefore, an alternative explanation for the underestimated variability in $\delta$ might be an underestimate of the diurnal cycle during moist days, which could be due to insufficient vertical mixing in the boundary layer in LMDZ.

[39] Finally, $\delta D$ variations associated with convection are maximum in the midtroposphere [Bony et al., 2008]. Simulated $\delta D$ fluctuations in spring and summer are 3 times larger at $500 \mathrm{hPa}$ than in the total column water. If the column water is not totally sampled but slightly biased toward higher altitudes, as suggested by the tendency of the SCIAMACHY instrument to underestimate precipitable water compared to ECMWF, this would also contribute to the higher observed variability than simulated.

\section{Influence of Large-Scale Dynamics, Convection, and Land Surface Recycling Diagnosed From Water-Tagging Experiments}

[40] In the previous section, we have shown that LMDZiso captures well the two regimes of vapor $\delta D$ control (subsidence in dry conditions or convection in wet conditions) and the time scales associated with the isotope response to convection. This gives us confidence that at first-order processes controlling the isotopic composition of water vapor and precipitation are well simulated. Therefore, we now use LMDZ-iso to investigate the influence of largescale dynamics (section 4.1), convection (section 4.2), and land surface recycling (section 4.3) on the water isotopic composition.

\subsection{Large-Scale Dynamics}

[41] At first order, the tropospheric humidity distribution can be understood by the last saturation paradigm: The specific humidity is determined by the saturation humidity 


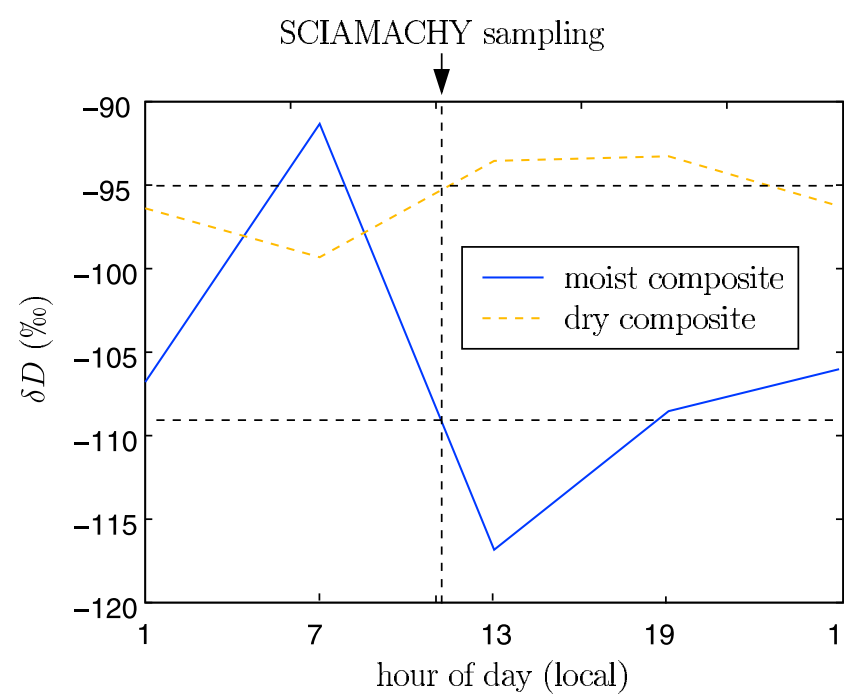

Figure 8. Composites of the diurnal evolution of $\delta D$ in column-integrated water vapor simulated by LMDZ in the control simulation. (Blue) Days in May and June when the precipitable water anomaly relatively to the seasonal cycle exceeds $0.8 \mathrm{~kg} / \mathrm{m}^{2}$. (Orange) Days in May and June when the precipitable water anomaly relatively to the seasonal cycle is lower than $-0.8 \mathrm{~kg} / \mathrm{m}^{2}$. Days used in the composites are colored in Figure 4. SCIAMACHY samples the Sahel everyday at about 10:00 universal time coordinated, corresponding to 11:00 local time.

the last time the air parcel has undergone saturation [Sherwood, 1996; Pierrehumbert and Roca, 1998]. Therefore, the specific humidity is all the lower as the last saturation has occurred at a much lower temperature, either at higher altitude or higher latitude. Similarly, last saturation temperature is expected to control the water vapor isotope composition [Galewsky et al., 2007; Galewsky and Hurley, 2010]. To quantify the dehydrating and depleting effect of last saturation temperature, in water-tagging experiment 1 we tag water vapor by the minimum temperature they have encountered since they have last evaporated from the surface [Risi et al., 2010a] (Appendix A2). We diagnose from this experiment an average minimum temperature $\left(T_{\min }\right)$ and average minimum humidity at saturation $\left(q_{\mathrm{smin}}\right)$ (Appendix A2).

[42] Vapor $\delta D\left(\delta D_{v}\right)$ and $T_{\min }$ have very similar distributions (Figure 9), suggesting that last saturation temperature controls at first order the spatial and seasonal variations of $\delta D_{v}$ in LMDZ-iso. At the intraseasonal scale, $\delta D_{v}$ is primarily controlled by a modulation of large-scale subsidence in dry conditions: over Niamey, for example, the daily correlation between $\delta D_{v}$ and $T_{\min }$ is 0.75 in DJF but only 0.19 in JJA. In wet conditions, $\delta D_{v}$ is more affected by convective processes (section 4.2), hence the weaker success of the last saturation paradigm in explaining isotope compositions (and so is the case for RH) [Emanuel and Pierrehumbert, 1996].

[43] Whereas the specific humidity is reset at its saturation value at each saturation event, $\delta D_{v}$ keeps some memory of processes anterior to the last saturation event: the higher $\delta D_{v}$ before the saturation, the higher $\delta D_{v}$ after the saturation.
Therefore, $\delta D_{v}$ may give some additional information regarding where the last saturation has taken place. Specifically, for a given saturation humidity, $\delta D_{v}$ is higher if saturation occurs in midlatitudes rather than in the tropical upper troposphere (Figure 10). This is likely due to surface evaporation recharging air masses in heavy isotopes as they move poleward [Noone, 2008]. Therefore, for a given humidity, $\delta D_{v}$ will be higher if dry air is transported equatorward from midlatitudes than if it is transported downward from the upper troposphere as part of the subsiding branch of the Hadley cell. The relative contribution of large-scale subsidence [Schneider et al., 2006; Couhert et al., 2010] versus isentropic transport from midlatitudes [Galewsky et al., 2005] in controlling the subtropical RH remains a subject of debate. The simulated isotopic difference between these two sources of moisture indicates the potential of $\delta D_{v}$ measurements to quantify these two contributions. For example, the underestimated depletion in the Sahara in LMDZ-iso may reflect an underestimated contribution of the subsiding branch of the Hadley cell versus meridional transport in the model.

[44] To summarize, as $\mathrm{RH}, \delta D_{v}$ is mainly controlled by the last saturation temperature in dry conditions. But in contrast to RH, it also keeps some memory of processes anterior to the last saturation, so it informs about dehydration pathways.

\subsection{Convection}

\subsubsection{Large-Scale Versus Local Controls}

[45] Two kinds of processes may significantly influence the seasonal and intraseasonal evolution of $\delta^{18} O_{p}$. First, processes along the air mass trajectories may affect the lowlevel vapor $\delta^{18} \mathrm{O}\left(\delta^{18} O_{v}\right)$ at the large scale, such as the depletion by mixing with unsaturated downdrafts [Risi et al., 2008a, 2008b, 2010a] and by rain reevaporation and isotopic exchanges between rain and water vapor [Lawrence et al., 2004; Worden et al., 2007; Field et al., 2010]. A change in large-scale $\delta^{18} O_{v}$ will be reflected into a change in $\delta^{18} O_{p}$ since the low-level vapor feeds convective systems and since the precipitation reequilibrates isotopically with this vapor as it falls. Second, rain-reevaporation and isotopic exchanges may lead to a local departure of $\delta^{18} O_{p}$ compared to $\delta^{18} O_{v}$, at the scale of the convective system that produces the precipitation. To better understand what controls $\delta^{18} O_{p}$, we thus decompose $\delta^{18} O_{p}$ into these two contributions as follows:

$$
\delta^{18} O_{p}=\delta^{18} O_{v}+\left(\delta^{18} O_{p}-\delta^{18} O_{v}\right)
$$

[46] The first and second terms represent the contributions of effect of large-scale processes and of local rain reevaporation processes respectively.

[47] Note that we assume that the effect of condensation altitude and processes do not contribute significantly to $\delta^{18} O_{p}$ [Risi et al., 2008a, 2010a; Yoshimura et al., 2010]. This is confirmed by tagging experiment 1: Except for drops condensing from vapor at temperatures lower than $243 \mathrm{~K}$, raindrops condensing from vapor at different minimum temperatures have exactly the same $\delta^{18} \mathrm{O}$ within $1 \%$. The few drops that have condensed at temperatures lower than 
a
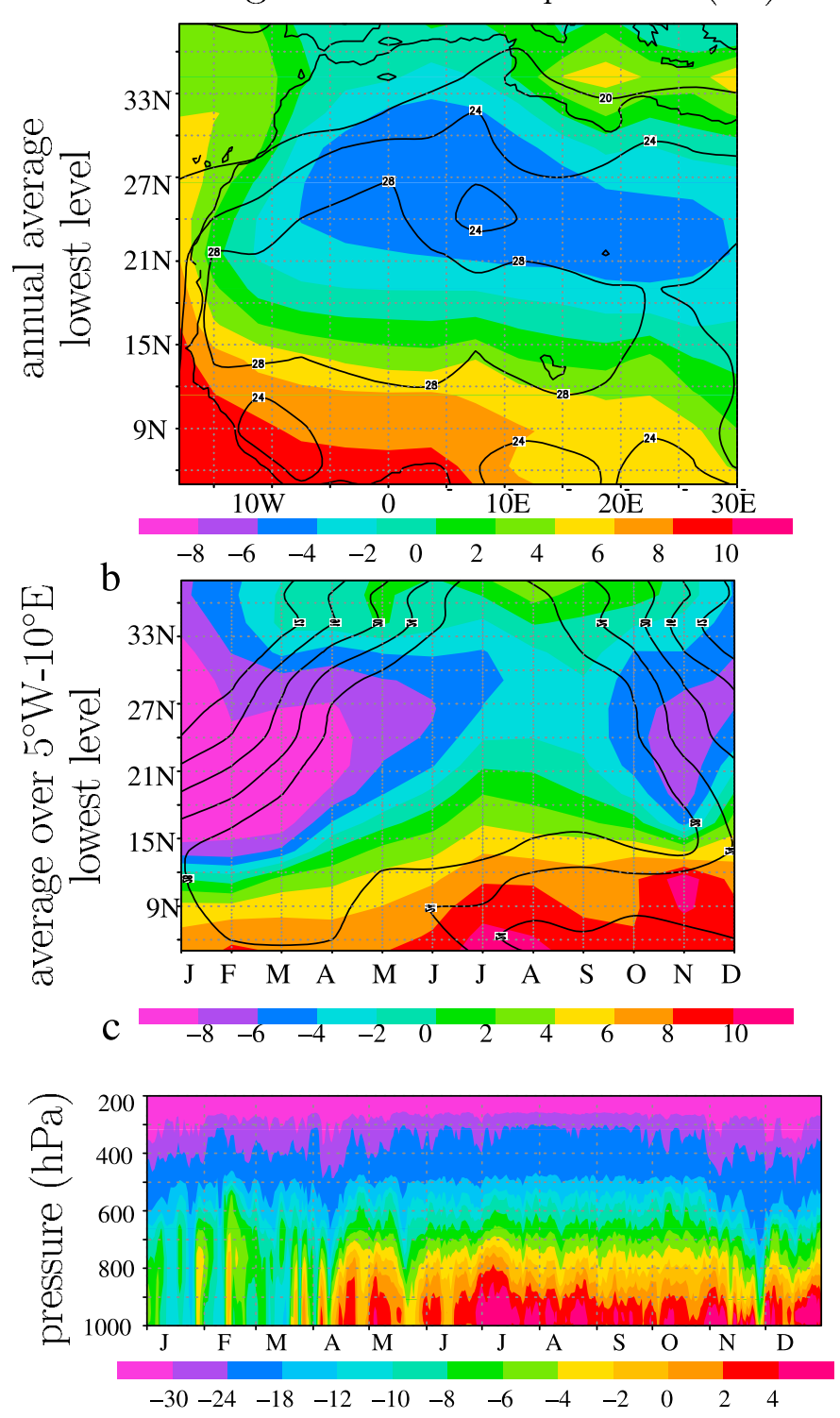
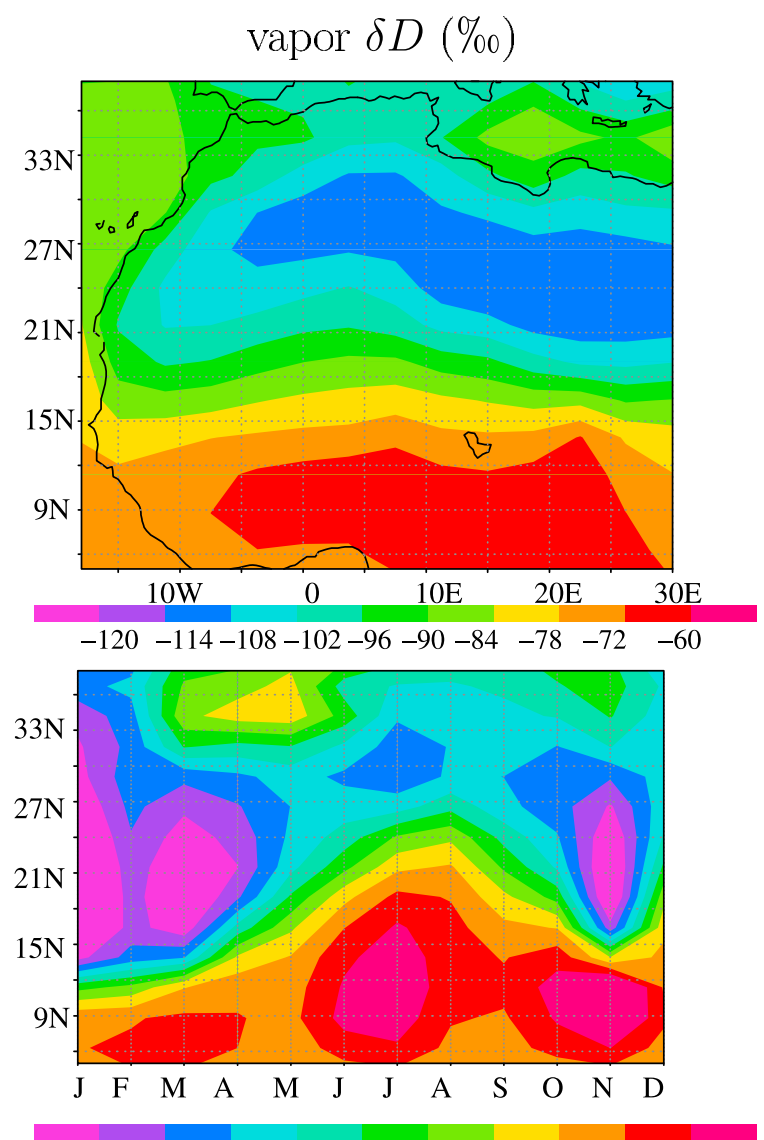

$-120-114-108-102-96-90-84-78 \quad-72 \quad-60$

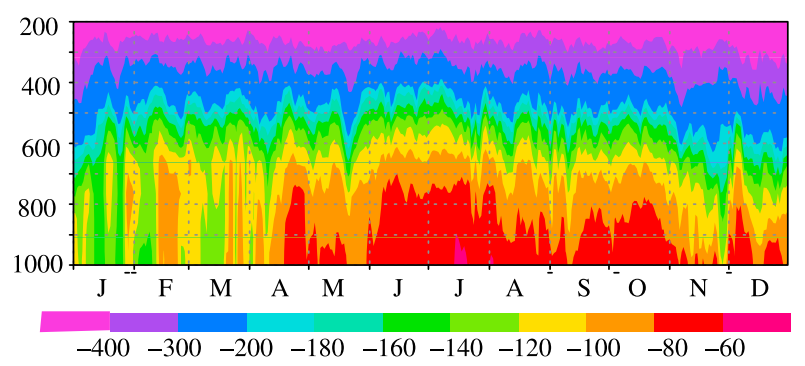

Figure 9. Relationship between the low-level vapor $\delta D$ and subsidence in LMDZ-iso. Minimum temperature undergone by water molecules (left) and $\delta D$ of the vapor (right). (a) Annual average at the lowest level, (b) monthly averages as a function of latitude averaged over $5^{\circ} \mathrm{W}-10^{\circ} \mathrm{E}$, and (c) daily profiles of Niamey. Contours show the surface temperature.

$243 \mathrm{~K}$ (less than $10 \%$ of the total precipitation) are on average $-3.5 \%$ more depleted than other drops. Since vapor at these very cold temperatures (corresponding to altitudes higher than $300 \mathrm{hPa}$ ) is $35 \%$ more depleted than at the surface, this shows that the signature of condensation height is at least $90 \%$ masked by reequilibration with the vapor as drops fall.

[48] We analyze the isotope variability over Niamey as an example. Before the onset, variations in local rain reevaporation explain $\delta^{18} O_{p}$ variations almost completely (Figure 11a, green). Positive peaks in $\delta^{18} O_{p}$ correspond to maxima in reevaporated fraction of raindrops and minima in $\mathrm{RH}$, in phase with minimum precipitation rates (Figures 11a and $11 \mathrm{~b})$. This is consistent with the instantaneous response of $\delta^{18} O_{p}$ to convection: Weak convective systems generally occur in dry environments associated with a strong reevaporation of the falling rain and thus with a richer precipitation. Similarly, $d_{p}$ is mainly controlled all along the monsoon by local rain reevaporation (Figure 11c).

[49] On the other hand, after the onset, $\delta^{18} O_{p}$ is controlled both by the rain reevaporation and by larger-scale processes (Figure 11, green and blue). Applying a methodology to quantify these two contributions detailed in Appendix B, we find that local rain reevaporation and large-scale processes explain $70 \%$ and $30 \%$ of the daily $\delta^{18} O_{p}$ variability respectively. These large-scale controls on $\delta^{18} O_{v}$ are the focus of the next section. 


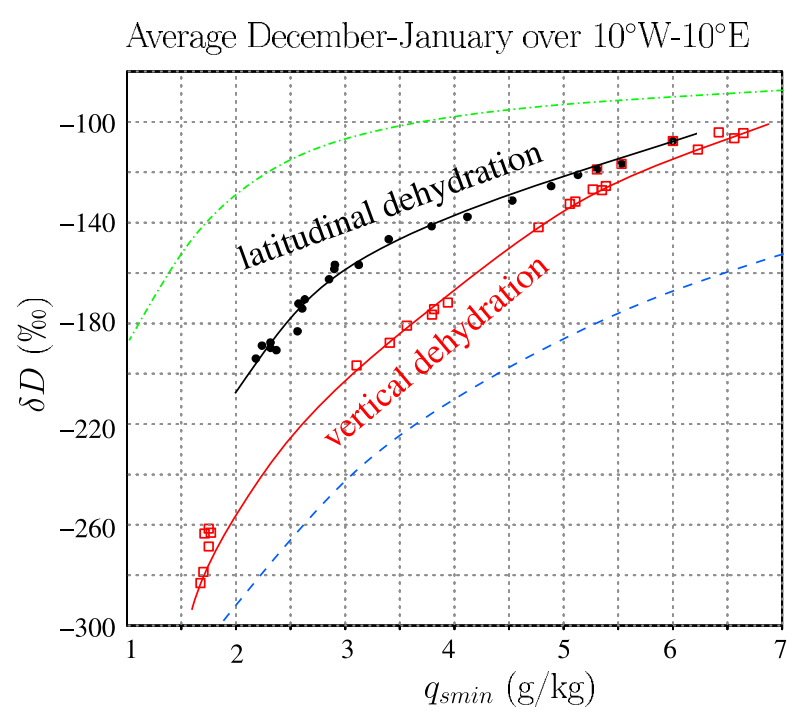

- $765 \mathrm{hPa}, 10^{\circ} \mathrm{N}-60^{\circ} \mathrm{N}$

므을 $0^{\circ} \mathrm{N}-10^{\circ} \mathrm{N}, 765-400 \mathrm{hPa}$

- - Rayleigh distillation starting at $900 \mathrm{hPa}$ at $10^{\circ} \mathrm{N}$

-... mixing line between vapor at $900 \mathrm{hPa}, 10^{\circ} \mathrm{N}$ and distilled vapor at $-30^{\circ} \mathrm{C}$

Figure 10. Vapor $\delta D$ as a function of saturation specific humidity at the minimum temperature undergone by the parcels $\left(T_{\min }\right)$ in winter, along a meridional transect (from $10^{\circ} \mathrm{N}$ to $60^{\circ} \mathrm{N}$ ) at $765 \mathrm{hPa}$ or along a vertical profile (from 765 to $400 \mathrm{hPa}$ ) in the West African tropics (between $0^{\circ} \mathrm{N}$ and $10^{\circ} \mathrm{N}$ ). All values are averaged over $10^{\circ} \mathrm{W}-10^{\circ} \mathrm{E}$ and DecemberJanuary 2006. The $765 \mathrm{hPa}$ level corresponds to the model level at which $\delta D$ is the closest from total column $\delta D$. Also shown are theoretical Rayleigh distillation and mixing lines starting from $900 \mathrm{hPa}$ at $10^{\circ} \mathrm{N}$ and ending at $-30^{\circ} \mathrm{C}$.

\subsubsection{Understanding Large-Scale Controls Through Water Tagging}

[50] To understand what processes affect $\delta^{18} O_{v}$ after the onset, we analyze the $\delta^{18} O_{v}$ variability over Niamey thanks to several water-tagging experiments.

[51] To quantify the possible effect of varying air mass origin [e.g., Araguas-Araguas et al., 1998], in tagging experiment 2 we tag evaporation from the different oceanic basins and from the continent [Koster et al., 1986; Delaygue et al., 2000; Werner et al., 2001; Noone and Simmonds, 2002b; Bosilovich and Schubert, 2002; Yoshimura et al., 2004]. In experiment 3 we tag water molecules that transit through each of three three-dimensional (3-D) domains, delimiting the three main air flows in the Sahel: the monsoon flow, advecting at low-levels moist and cool air from the southwest, the Harmattan, advecting dry and warm air from the Sahara and the African easterly jet, advecting moist air at midlevels from the east (Appendix A3). We found little correlation between $\delta^{18} O_{v}$ and the relative proportions or compositions of vapor from different oceanic basins or from different air flows at the seasonal and intraseasonal time scales (not shown). This shows that physical processes along trajectories, rather than the geographic origin of water, control the isotope composition at these time scales. More specifically, the variability in $\delta^{18} O_{v}$ reflects mainly that in the monsoon flow vapor, which is the main source of moisture in Niamey.

[52] To disentangle the effect of continental recycling from other processes along trajectories, in tagging experiment 2 we tag the water that evaporates over land versus ocean. We find that variations in $\delta^{18} \mathrm{O}$ of the oceanic vapor $\left(\delta^{18} O_{\text {oce }}\right)$ are in phase with those of $\delta^{18} O_{v}$ but with much larger amplitudes (Figure 12a, blue), whereas the contribution of continental $\delta^{18} \mathrm{O}$ is out of phase with $\delta^{18} O_{v}$, especially after the monsoon onset (Figure 12a, green). This shows that variations in $\delta^{18} O_{v}$ are mainly driven by variations in $\delta^{18} O_{\text {oce }}$ and dampened by continental recycling. We estimate (following Appendix $\mathrm{C}$ ) that variations in the oceanic and continental vapor $\delta^{18} \mathrm{O}$ vapor account for $110 \%$ and $-50 \%$ respectively of the amplitude of $\delta^{18} O_{v}$ variations.

[53] What processes along trajectories explain variations in $\delta^{18} O_{\text {oce}}$ ? Convective mixing by unsaturated downdrafts has a strong depleting impact on the lower tropospheric vapor [Risi et al., 2008a] (N. Kurita et al., Water vapor recycling induced by the MJO convection, submitted to Journal of Geophysical Research, 2010). To quantify this effect, in tagging experiment 4 we tag the water vapor that has gone through unsaturated downdrafts in the convective parametrization at least once since they have last evaporated from the surface. This experiment shows that the $\delta^{18} O_{v}$ variability is mainly driven by variations in the $\delta^{18} \mathrm{O}$ of the vapor having been through unsaturated downdrafts $\left(\delta^{18} O_{\mathrm{ddft}}\right)$ relatively to that of the remaining vapor (Figure $12 \mathrm{~b}: 120 \%$ of $\delta^{18} O_{v}$ variability). This contribution is anticorrelated with precipitation averaged over the 10 to 20 previous days over a wide Sahelian area and along the monsoon trajectories (not shown). The progressive depletion of vapor by unsaturated downdrafts thus explains the temporal and spatial integration of the convective signal by $\delta^{18} O_{v}$. On the other hand, stronger recycling by surface evaporation during these convective phases slightly dampen this depletion $(-30 \%)$.

[54] Why are unsaturated downdrafts more depleted as convection increases? First, they bring vapor down more quickly from higher up into the boundary later [Risi et al., 2008a]. Second, in a moister air, the vapor of unsaturated downdrafts becomes less enriched by rain reevaporation and more depleted by diffusive exchanges with the rain [Lawrence and Gedzelman, 1996; Risi et al., 2008a]. These two effects are supported by tagging experiment 5 in which we tag precipitation reevaporation (Figure 12c): $54 \%$ of $\delta^{18} O_{v}$ variability is explained by more depleted rain reevaporation in wetter conditions. The remaining is explained by $\delta^{18} O_{v}$ variability in the remaining vapor, likely due to stronger downdrafts bringing vapor from higher up. To summarize, in wet conditions $\delta^{18} \mathrm{O}$ integrates convective activity trough progressive depletion of the vapor by unsaturated downdrafts along air mass trajectories and rain reevaporation accounts for half of this depletion.

[55] Conversely, may we use the isotopic composition of water vapor to design diagnostics that quantify the contribution of rain reevaporation to the lower tropospheric moistening as suggested by Worden et al. [2007]? When tuning a parameter in the convective scheme to double rain reevaporation, the contribution of rain reevaporation to $\delta^{18} O_{v}$ intraseasonal variability increases from half to $66 \%$ 


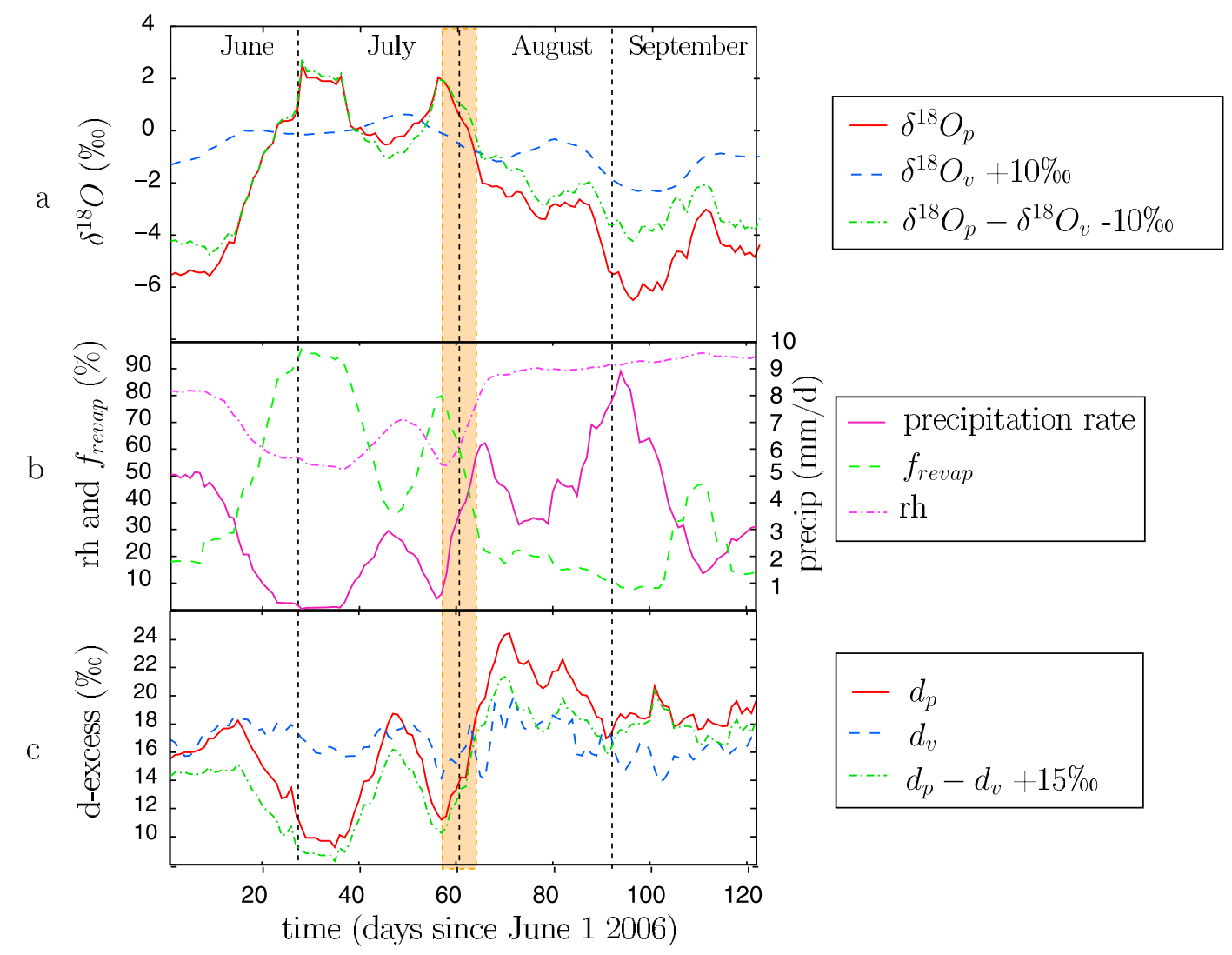

Figure 11. (a) Daily $\delta^{18} \mathrm{O}$ in the precipitation $\left(\delta^{18} O_{p}\right.$, red) and in the lowest level vapor $\left(\delta^{18} O_{v}\right.$, blue), and the difference $\delta^{18} O_{p}-\delta^{18} O_{v}$ (green), simulated by LMDZ-iso. (b) Precipitation rate, relative humidity of the lowest level air, and reevaporated fraction of the rain, simulated by LMDZ-iso. (c) Same as a but for d-excess. To better compare the different curves on the same plots, we added $10 \%$ to $\delta^{18} O_{v}$, subtracted $10 \%$ to $\delta^{18} O_{p}-\delta^{18} O_{v}$ and added $15 \%$ to $d_{p}-d_{v}$. All time series have been applied a 5 day running mean. The period of the monsoon onset is highlighted as an orange rectangle.

(not shown). However, this is compensated by a slightly reduced convective activity, so that in the end both simulations have nearly identical $\delta^{18} O_{v}$. On the other hand, doubling rain reevaporation increases $d_{v}$ by $2 \%$ in average after the onset. This suggests $d_{v}$ measurements may provide complementary information to $\delta^{18} O_{v}$ to disentangle the relative effect of depletion by rain reevaporation and by other convective processes. However, first $d_{v}$ measurements would be necessary to assess the credibility of $d_{v}$ in LMDZ-iso.

\subsection{Continental Recycling}

\subsubsection{Role of Land Surface Processes in Controlling Vapor and Precipitation Isotopes}

[56] To investigate further the effect of continental recycling, in tagging experiment 6 we tag continental evaporation depending on whether it originates from transpiration (with the composition of the soil water: Washburn and Smith [1934]; Barnes and Allison [1988]) or bare soil evaporation (more depleted than the soil water due to fractionation: Barnes and Allison [1983]; Allison et al. [1983]; Moreira et al. [1997]) in a simulation coupled to ORCHIDEE-iso. As air moves inland, its oceanic vapor gets depleted by convection, but this is compensated by an increase in the proportion of enriched vapor from continental recycling $\left(\delta^{18} O_{\text {con }}\right)$, leading to an almost constant $\delta^{18} O_{v}$ along trajectories (Figures 13a and 13b). This vapor is more enriched because it arises from previous precipitation mainly by transpiration, which does not fractionate [Washburn and Smith, 1934; Barnes and Allison, 1988; Moreira et al., 1997]. Fractionation during bare soil evaporation has a relatively small impact on $\delta^{18} O_{v}\left(\delta^{18} O_{\text {con }}\right.$ is only $3 \%$ more depleted than would be the case if continental vapor originated from transpiration only) but has a much stronger on $d_{v}$ [Gat and Matsui, 1991]: Vapor from continental recycling in Niamey has a d-excess $13 \%$ higher than would be the case with transpiration only (not shown). To summarize, $\delta^{18} O_{v}$ reflects the continental recycling intensity while $d_{v}$ reflects more the partitioning of this recycling into bare soil evaporation and transpiration.

\subsubsection{Inferring Continental Recycling Using Isotope Gradients}

[57] Since continental recycling partly compensate for the convective depletion along trajectories (Figure 13), $\delta^{18} O_{v}$ gradients along trajectories should give information about the continental recycling intensity. To what extent could we use these $\delta^{18} O_{v}$ gradients (e.g., as observed by SCIAMACHY or by a network of in situ instruments) to quantify continental recycling? Using a simple budget equation, we show that a continental recycling proxy could be theoretically estimated 


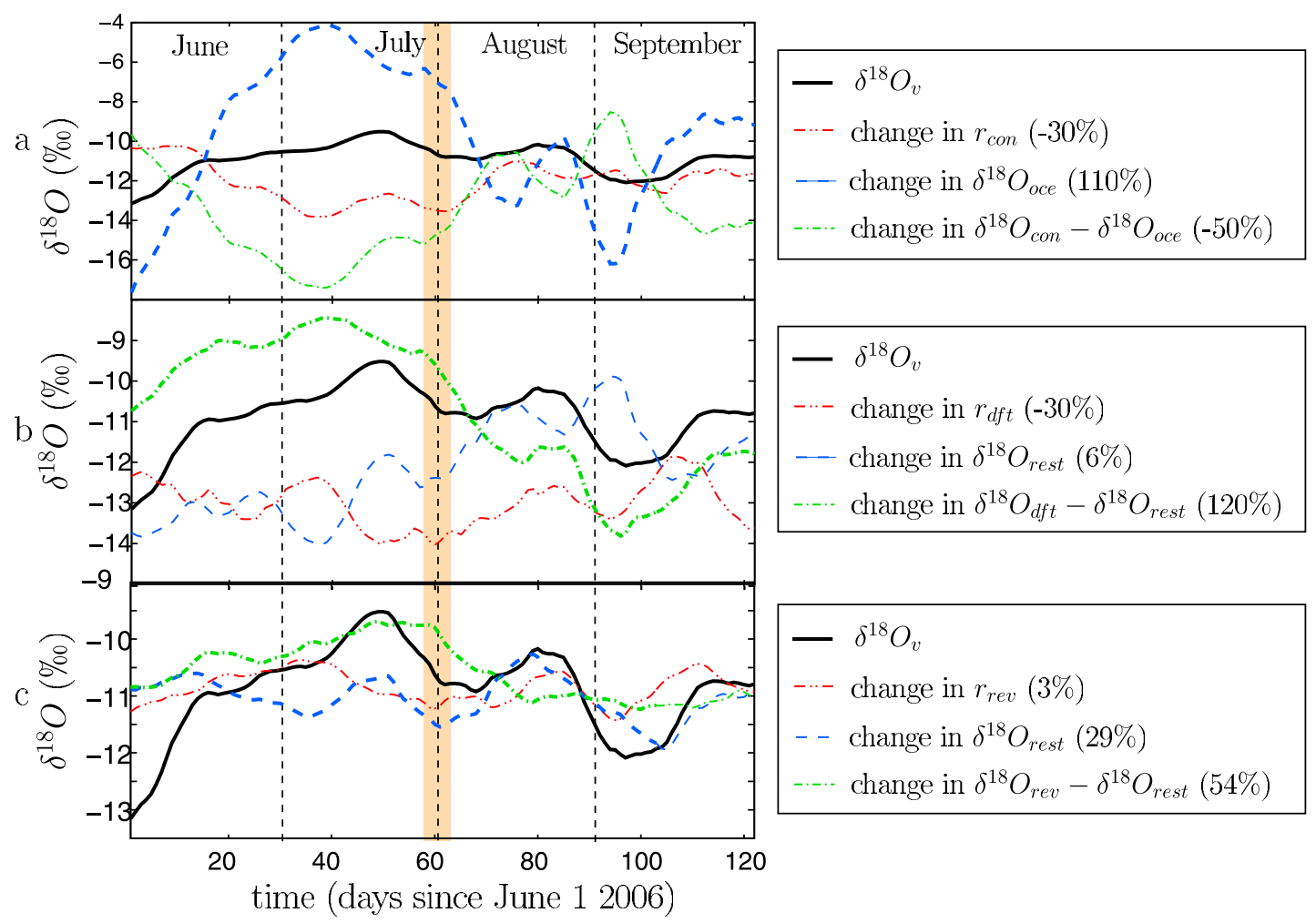

Figure 12. Contribution of vapor recycling by land surface evaporation, unsaturated downdrafts, and rain reevaporation to the intraseasonal variability in $\delta^{18} O_{v}$ as decomposed following Appendix C. (a) $\delta^{18} \mathrm{O}$ in the total vapor at the lowest level over Niamey (thick solid black) and the three contributions to its variability diagnosed from the continental recycling tagging experiment: change in continental proportion (dotted red), change in oceanic vapor $\delta^{18} O$ (dashed blue), and change in the relative $\delta^{18} O$ of the continental and oceanic vapor (dash-dotted green). (b) Same as Figure 12a but for the unsaturated downdraft tagging experiment: change in downdraft proportion (dotted red), change in residual vapor $\delta^{18} O$ (dashed blue), and change in the relative $\delta^{18} O$ of the downdraft and residual vapor (dash-dotted green). (c) Same as Figure 12a but for the precipitation reevaporation tagging experiment: change in the proportion of vapor arising from precipitation reevaporation (dotted red), change in residual vapor $\delta^{18} O$ (dashed blue), and change in the relative $\delta^{18} O$ of the reevaporation and residual vapor (dash-dotted green). The subscripts con, oce, dft, rev, and rest denote the continental vapor, oceanic vapor, downdraft vapor, reevaporation vapor, and remaining vapor, respectively. All time series have been applied a 5-day running mean. All contributions have been added the average $\delta^{18} O_{v}$ for visualization purpose. The major contributions are highlighted by thicker lines. The percentage numbers in parentheses in the key result from the quantification method described in Appendices B and C. The period of the monsoon onset is highlighted as an orange rectangle.

by measuring $\delta_{v}$ and $\delta_{p}$ along air mass trajectories (Appendix D)

$$
d\left(\frac{r_{\mathrm{con}}}{1-r_{\mathrm{con}}}\right) / d x=\frac{d \delta_{v} / d x-d \delta_{\mathrm{voce}} / d x}{\delta_{p}-\delta_{v}},
$$

where $r_{\text {con }}$ is the proportion of the vapor originating from continental evaporation, and $\delta_{\text {voce }}$ and $\delta_{\text {vcon }}$ are the $\delta$ of the vapor originating from ocean and continental evaporation respectively. To quantify the accuracy of such an estimate, we compare $d\left(\frac{r_{\text {con }}}{1-r_{\text {con }}}\right) / d x$ inferred from isotopes in LMDZiso to that diagnosed from water tagging, over Niamey as an example. If we know $\frac{d \delta_{\text {voce }}}{d x}$, then $d\left(\frac{r_{\text {con }}}{1-r_{\text {con }}}\right)$ can be estimated with a reasonable precision (Figure 14, red): the correlations between simulated and reconstructed recycling proxy are
0.98 and 0.95 at the monthly and daily scales respectively, and the root-mean-square errors are 0.06 and 0.11 respectively. However, $\frac{d \delta_{\text {voce }}}{d x}$ strongly depends on convective activity (section 4.2.2) whose isotopic response is difficult to quantify directly from observations. It anticorrelates with the precipitation integrated along the trajectory $(\bar{P})$ with $r=$ -0.63 at the daily time scale in summer. Assuming a linear

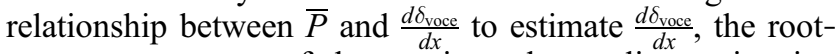
mean-square error of the continental recycling estimation increases to 0.24 and 0.21 at the monthly and daily time scales respectively (Figure 13, green), corresponding to an accuracy of $50 \%$ at best on the recycling proxy.

[58] To summarize, if the effect of convective processes on the isotopic composition of water vapor was very well understood and could be quantified, then the intensity of 

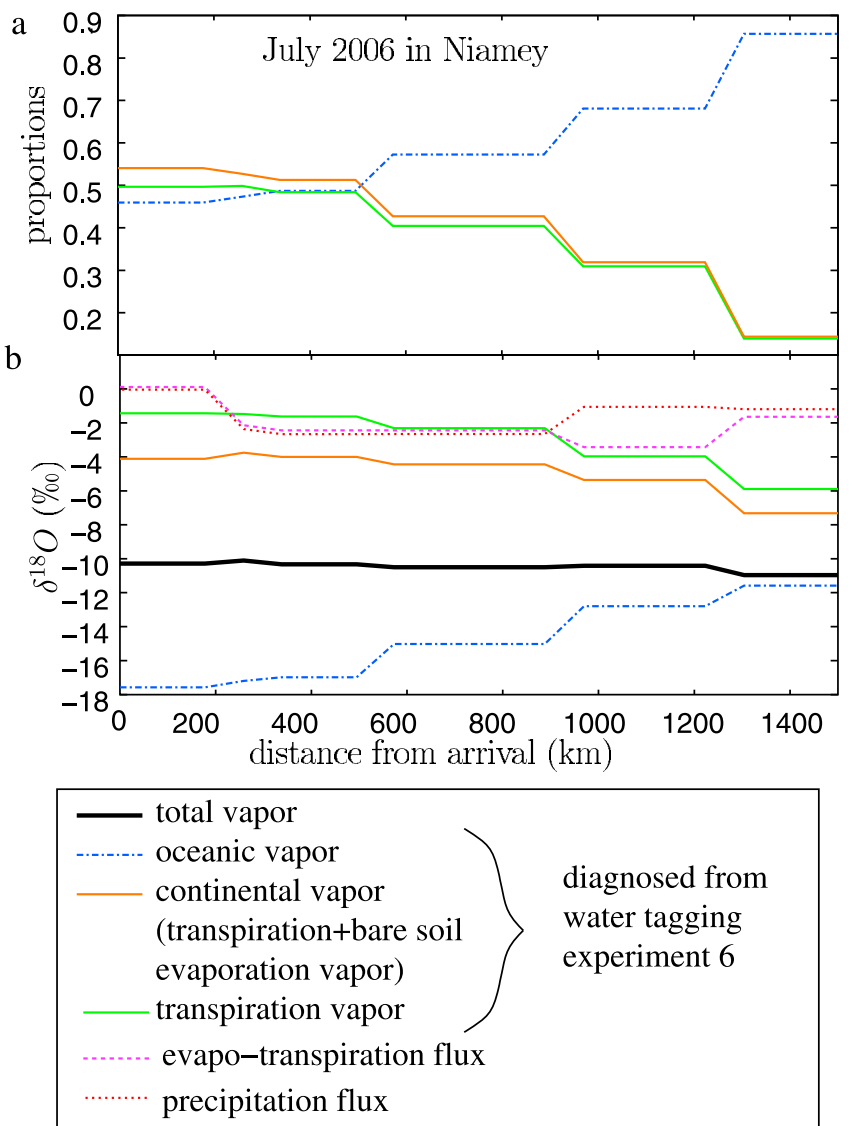

Figure 13. (a) Evolution of the relative proportion of the lowest level vapor having evaporated over land (brown) and ocean (blue) along the monthly trajectory to Niamey in July 2006 simulated by LMDZ-iso coupled to ORCHIDEE and diagnosed from water-tagging experiment 6 . The proportion of vapor having evaporated over land through transpiration (as opposed to bare soil evaporation) is also shown (green). (b) Same as for Figure 13a but for $\delta^{18} \mathrm{O}$ of the vapor from different origins. The composition of the total vapor (black), evapotranspiration (magenta), and precipitation (red) fluxes are also shown.

continental recycling could be inferred from a single isotopologue with a good accuracy. However, quantifying the effect of convective processes remains the key uncertainty.

\section{Conclusion}

\subsection{Summary}

[59] The goal of this study was to investigate the added value of water isotope measurements to better understand and estimate the hydrological cycle in the Sahel and to better evaluate its representation in atmospheric GCMs.

[60] First, comparing the LMDZ GCM with several satellite and in situ data sets documenting the isotopic composition of vapor and precipitation, we show that the model is able to represent the main controls of the water isotopic composition at the intraseasonal to seasonal time scales. However, several isotopic biases of the model (excessive enrichment and underestimated seasonal and intraseasonal variability) are not directly associated with biases in humidity, highlighting the added value of water isotopes to detect the misrepresentation of hydrological processes that would go undetected otherwise.

[61] Second, understanding what controls the isotopic composition of water vapor and precipitation is a first step toward assessing their added value to better understand the hydrological cycle. Using a novel water-tagging approach, we disentangled and quantified the relative effect of largescale circulation, convection, and continental recycling at the seasonal and intraseasonal time scales (Figure 15). In particular, we highlight the important role of large-scale subsidence in dry conditions and of unsaturated downdrafts, rain reevaporation, and isotope exchanges between rain and water vapor in wet conditions.

[62] Third, at the light of this improved understanding of the isotopic signal, we show that (1) the isotopic composi-

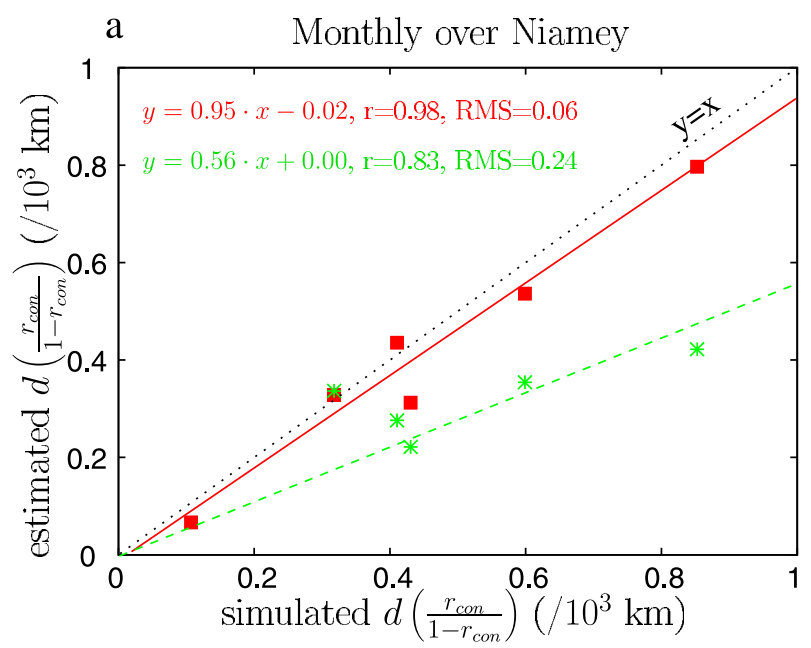

b Daily in June-July 2006 over Niamey

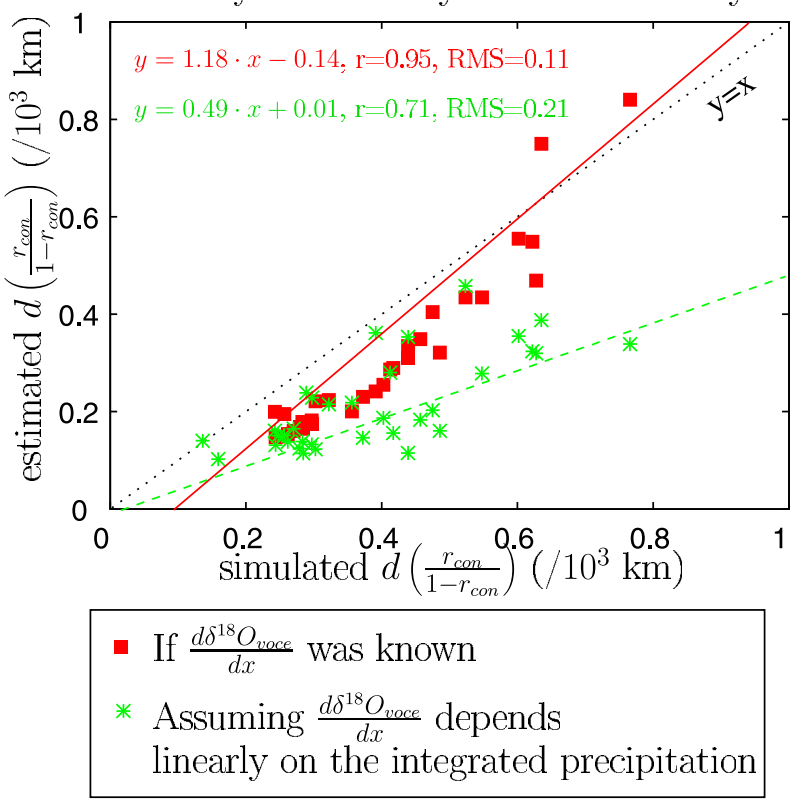

Figure 14. Accuracy of a method to estimate continental recycling from vapor and precipitation $\delta^{18} \mathrm{O}$ measurements, applied over Niamey for the LMDZ-ORCHIDEE simulation as an example. (a) At the monthly scale; (b) at the intraseasonal scale during June to September. See text for details. 
a
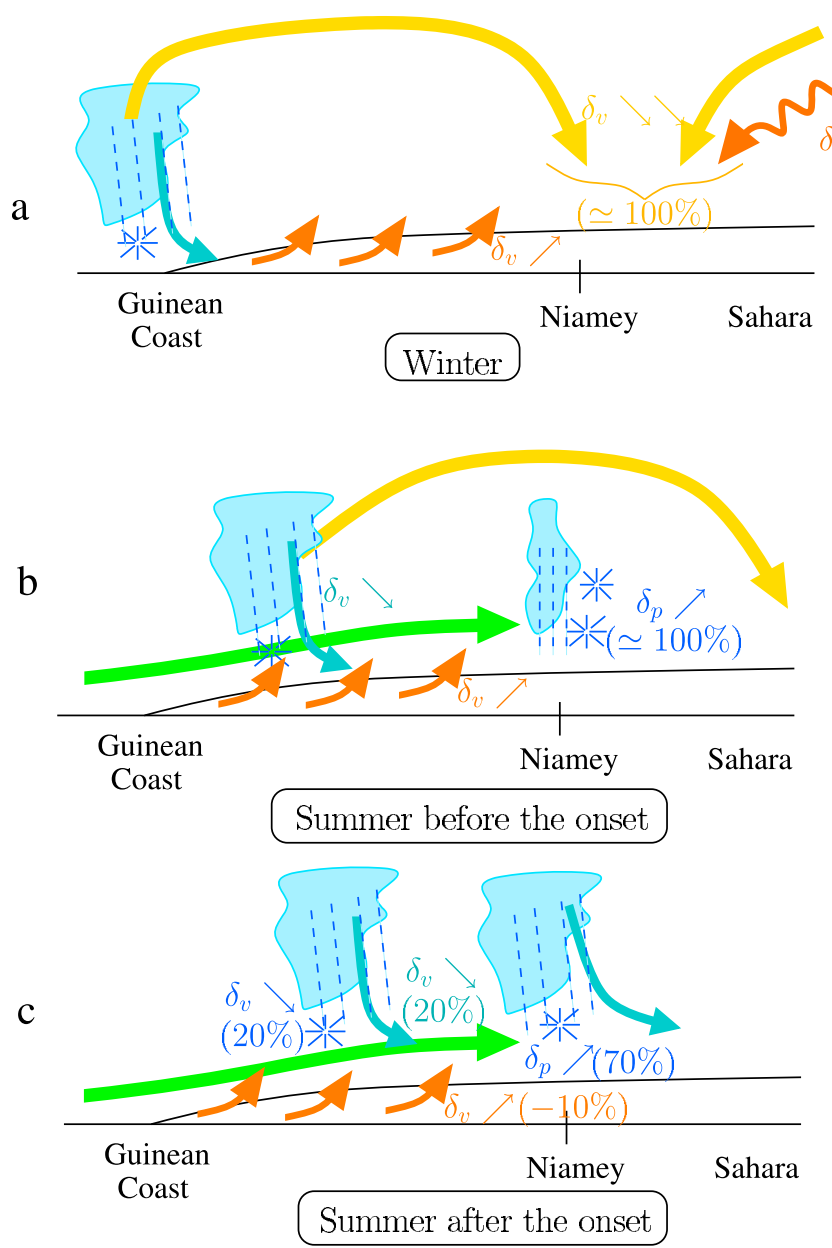

\begin{tabular}{|c|c|}
\hline & $\begin{array}{l}\text { large-scale subsidence } \\
\text { associated with the } \\
\text { Hadley circulation }\end{array}$ \\
\hline & $\begin{array}{l}\text { eddy transport from } \\
\text { mid-latitudes }\end{array}$ \\
\hline & continental recycling \\
\hline & unsaturated downdraft \\
\hline & rain reevaporation \\
\hline & isolated convection \\
\hline & $\begin{array}{l}\text { organized, frequent } \\
\text { convection associated } \\
\text { with the ITCZ }\end{array}$ \\
\hline$(20 \%)$ & $\begin{array}{l}\text { contribution to the } \\
\text { intra-seasonal variability } \\
\text { of } \delta_{p} \text { at Niamey }\end{array}$ \\
\hline
\end{tabular}

Figure 15. Summary of our understanding of the relative influence of the large-scale dynamics, convection, and continental recycling on the vapor and precipitation composition in the Sahel. The percentages represent the contribution of the different processes to the intraseasonal variability of precipitation $\delta$ at Niamey as deduced from our water tagging analysis. (a) During the winter season, the vapor $\delta$ is controlled by the intensity of large-scale subsidence associated with the descending branch of the Hadley cell and by dry air advection from midlatitude eddies. (b) In summer before the monsoon onset, variations in vapor $\delta$ may be associated with the varying development of the boundary layer. The precipitation $\delta$ and dexcess are controlled locally by the intensity of rain reevaporation. (c) In summer after the monsoon onset, variations in vapor $\delta$ explain $30 \%$ of variations in precipitation $\delta$ and local rain reevaporation explains the remaining $70 \%$ (and the totality of precipitation d-excess variations). The vapor $\delta$ is mainly controlled by regional and upstream convective activity, through progressive depletion by unsaturated downdrafts along trajectories. Rain reevaporation in these downdrafts and their dynamic effect contribute each to half of the intraseasonal variations in vapor $\delta$ (i.e., each $20 \%$ of the variability of the precipitation). At all times, continental recycling dampens the depleting effect of large-scale subsidence or convection along trajectories.

tion of water vapor may help quantify the relative contribution of two dehydration pathways in the subtropics, namely dehydration in the tropical upper troposphere versus in mid latitudes [Schneider et al., 2006], and (2) continental recycling could be inferred from water vapor measurements provided that the influence of convective processes on the isotopic depletion along trajectory, which is still a major uncertainty, could be quantified.

\subsection{Perspectives}

[63] This study demonstrates on a regional case study the power of diagnostic tools provided by isotopic GCMs, in particular water tagging. The Sahel constitutes an interesting case study where large-scale dynamics, convection and continental recycling all play a key role in the regional moisture budget [Hall and Peyrillé, 2006], but this kind of modeling approach could be readily extended to other regions in the future.

[64] The strong underestimate of the intraseasonal variability in vapor $\delta D$ in LMDZ-iso compared to SCIAMACHY and TES, while the intraseasonal variability in precipitable water, relative humidity, and $\delta D$ in precipitation is acceptable, raises questions. The development of GCM simulators of satellite data, which emulate what the satellite instrument would retrieve if it was flying in the world of the GCM, is now commonplace to compare water vapor or cloud satellite 


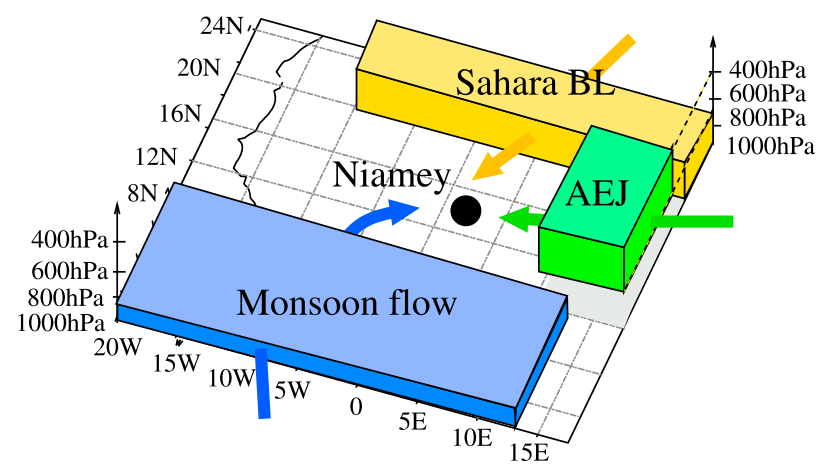

Figure A1. Definition of the 3-D tagged domains for tagging experiment 3: monsoon flow, African Easterly Jet (AEJ) and Sahara boundary layer (Sahara BL).

data to GCMs in a consistent way [e.g., Yu et al., 1996; Roca et al., 1997; Klein and Jakob, 1999; Webb et al., 2001; Haynes et al., 2007; Chepfer et al., 2008]. Development of this model-to-satellite approach for isotopic retrievals may permit a more rigorous model-data comparison and a better quantification of the different sources of disagreement. Moreover, the development of in situ vapor measurements with new laser spectroscopy techniques [Gupta et al., 2009] will allow us to monitor the intraseasonal variability in isotopes with a higher temporal resolution and to document the diurnal cycle that may significantly affect the $\delta D$ observed by satellite over tropical continental regions.

[65] We have shown that the influence of convective processes on the water vapor composition remains difficult. In the future, incorporating water isotopologues in a cloud resolving model and increased observations of water vapor isotopes will help gain better insight into how convective processes affect the isotope composition at the mesoscale.

[66] We have shown that the diurnal cycle may play a key role in the intraseasonal isotope variability. Dramatic improvements are expected in the CMIP5 version of LMDZ, with a boundary layer scheme including thermal plumes and associated moist processes [Rio and Hourdin, 2007] coupled to the convective scheme, which allows to capture the smooth transition from shallow to deep convection during the diurnal cycle [Rio et al., 2009]. Moreover, the CMIP5 version will include a parameterization of cold pools generated by the reevaporation of the convective rainfall [Grandpeix and Lafore, 2010; Grandpeix et al., 2010], which will allow an implicit representation of the degree of organization of convection and may increase the currently underestimated isotopic variations associated with convection. In the future, we will explore how measurements of the water isotopic composition could be used as an additional evaluation tool for model parameterizations.

\section{Appendix A: Water-Tagging Experiments}

\section{A1. General Principle}

[67] The principle of our water-tagging experiments is very similar to that of Joussaume et al. [1984], Koster et al. [1986, 1992], Cole et al. [1999], Delaygue et al. [2000], Werner et al. [2001], Noone and Simmonds [2002b], Vuille et al. [2003], Yoshimura et al. [2004], and Frankenberg et al. [2009] tagging the evaporative origin and those of Galewsky et al. [2005], Hurley and Galewsky [2010], and Wright et al. [2010] tagging 3-D domains of last saturation. A number $n$ of new tracers are added for each isotopic species $i$, including $\mathrm{H}_{2}^{16} \mathrm{O}$, so

$$
q_{i}=\sum_{j=1}^{n} x_{i, j},
$$

where $q_{i}$ is the mixing ratio of the total isotope species and $x_{i, j}$ are the mixing ratios of the additional tracers for the traditional isotope species $i$. This definition requires us to run a new simulation for each tagging experiment but allows us to check mass conservation.

[68] All tagging tracers are passive and have influence neither on the hydrological cycle nor on isotopic processes. These tracers undergo exactly the same processes as traditional isotopologues, except those processes targeted by the experiment. During condensation, the isotopic ratio of droplets for each tag is calculated from that of the vapor of the same tag, so droplets record the influence of moisture origin on the composition of the vapor they condense from. On the other hand, each tracer in raindrops reequilibrates isotopically with the total vapor, because reequilibration tends to homogenized the rain composition toward an equilibrium with the ambient vapor.

[69] Tracers behave differently only for processes targeted by the experiment. For example, in experiment 2, tagging evaporative origin, only the tracer corresponding to the geographical location is created during surface evaporation. In experiment 4 , tagging unsaturated downdrafts, all tracers are converted into the unsaturated downdraft tag as soon as they enter an unsaturated downdraft.

\section{A2. Tagging the Minimum Temperature Encountered}

[70] This tagging experiment was described in Risi et al. [2010a]. It is similar to those of Galewsky et al. [2005], Hurley and Galewsky [2010], and Wright et al. [2010], except that here we tag directly the minimum temperature, whereas they tagged the saturation altitude and latitude. A tag is attributed to each of five temperature bins: higher than $293 \mathrm{~K}, 293 \mathrm{~K}$ to $284.3 \mathrm{~K}, 284.3 \mathrm{~K}$ to $267.7 \mathrm{~K}, 267.7 \mathrm{~K}$ to $243 \mathrm{~K}$, and lower than $243 \mathrm{~K}$. At each GCM time step, the fraction of the vapor whose temperature is lower than the temperature of its tag is retagged with the tag corresponding to its temperature. Therefore, the total water vapor and its isotopologues are mixtures of water vapor of different tags representing the minimum temperatures they have encountered.

[71] We diagnose in each grid box the average minimum temperature encountered $T_{\min }$ as [Risi et al., 2010a]

$$
T_{\min }=\sum_{i=1}^{5} r_{i} T_{\mathrm{bin}, i}
$$

where $r_{i}$ is the proportion of water molecules with tag $i$ and $T_{\text {bin, } i}$ the average temperature of each bin $i$. We approximate $T_{\text {bin, } i}$ to $296 \mathrm{~K}, 289 \mathrm{~K}, 276 \mathrm{~K}, 256 \mathrm{~K}$, and $240 \mathrm{~K}$ respectively for the different bins. 


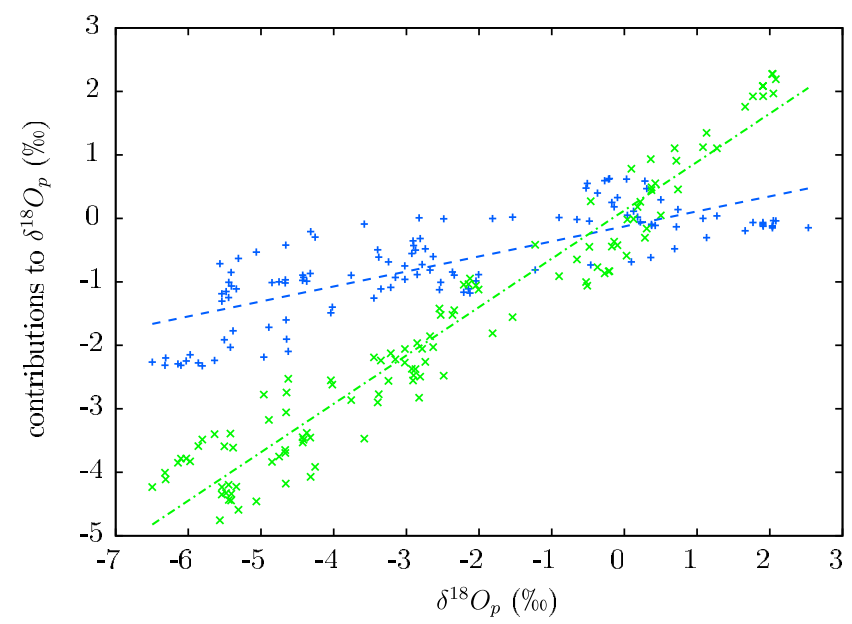

$+\quad$ contribution from $\delta^{18} O_{v}$
$\times \quad$ contribution from $\delta^{18} O_{p}-\delta^{18} O_{v}$
linear regressions
$-y=24 \cdot x-0.13 \longrightarrow 24 \%$ of $\delta^{18} O_{p}$ signal
$-y=76 \cdot x+0.13 \longrightarrow 76 \%$ of $\delta^{18} O_{p}$ signal

Figure B1. Illustration of our method to decompose the isotopic variability into different contributions as explained in Appendix B: example for decomposing the $\delta^{18} O_{p}$ signal into a large-scale signal $\left(\delta^{18} O_{v}\right.$, blue $)$ and a local effect of rain reevaporation and isotopic exchanges between rain and vapor $\left(\delta^{18} O_{p}-\delta^{18} O_{v}\right.$, green). The daily time series of these two contributions (as plotted in Figure 11a) are plotted as a function the daily time series of $\delta^{18} O_{p}$. We added $10 \%$ and $-10 \%$ o to $\delta^{18} O_{v}$ and $\delta^{18} O_{p}-\delta^{18} O_{v}$ for visualization purpose only. The slope of the linear regression indicates the fraction of the $\delta^{18} \mathrm{O}$ variability explained by each of these two contributions: $24 \%$ for $\delta^{18} O_{v}$ and $76 \%$ for $\delta^{18} O_{p}-\delta^{18} O_{v}$. We check that the sum of these two contributions equals $100 \%$.

[72] Similarly, we diagnose the average minimum saturation humidity encountered $q_{\text {smin }}$ as:

$$
q_{\mathrm{smin}}=\sum_{i=1}^{5} r_{i} q_{s}\left(T_{\mathrm{bin}, i}, P_{\mathrm{bin}, i}\right),
$$

where $q_{s}$ is the specific humidity at saturation and $P_{\mathrm{bin}, i}$ is the average pressure of each bin, approximated following an average temperature profile over $30^{\circ} \mathrm{S}-30^{\circ} \mathrm{N}$.

\section{A3. Tagging the Main Air Flows to the Niamey Area}

[73] To investigate the effect of varying air mass origin, in tagging experiment 3 we tag water vapor that transits through each of three 3-D domains, delimiting the three main air flows in the Sahel (Figure A1): the monsoon flow $\left(5^{\circ} \mathrm{S}-8^{\circ} \mathrm{N}, 40^{\circ} \mathrm{W}-15^{\circ} \mathrm{E}, 1000-850 \mathrm{hPa}\right)$, the Harmattan $\left(20^{\circ} \mathrm{N}-30^{\circ} \mathrm{N}, 10^{\circ} \mathrm{W}-40^{\circ} \mathrm{E}, 1000-700 \mathrm{hPa}\right)$, and the African easterly jet $\left(8^{\circ} \mathrm{N}-20^{\circ} \mathrm{N}, 10^{\circ} \mathrm{E}-30^{\circ} \mathrm{E}, 700-400 \mathrm{hPa}\right)$. As soon as water vapor enters one of these domains, it gets the tag of this domain. This tag is lost when water vapor enter another domain or precipitate. Evaporation from the surface is tagged with a fourth tag.

\section{Appendix B: Quantifying Several Contributions to an Isotopic Signal}

[74] The goal is to decompose the simulated isotopic variability into several contributions. As an example, we explain here and illustrate in Figure B1 how to decompose the $\delta^{18} O_{p}$ signal into a large-scale signal $\left(\delta^{18} O_{v}\right)$ and a local effect of rain reevaporation and isotopic exchanges between rain and vapor $\left(\delta^{18} O_{p}-\delta^{18} O_{v}\right)$ (section 4.2). The sum of these two contributions equals the signal of interest $\delta^{18} O_{p}$. The daily time series of these two contributions (as plotted in Figure 11a) are plotted as a function the daily time series of $\delta^{18} O_{p}$. The slope of the linear regression indicates the fraction of the $\delta^{18} \mathrm{O}$ variability explained by each of these two contributions: $24 \%$ for $\delta^{18} O_{v}$ and $76 \%$ for $\delta^{18} O_{p}-$ $\delta^{18} O_{v}$. We check that the sum of these two contributions equals $100 \%$.

[75] This method can be generalized to decompositions with more than two contributions. Note that the quantification of the different contributions may not always sum up to $100 \%$ due to nonlinearity or when the different terms are not all in phase.

\section{Appendix C: Understanding Isotopic Variations Using Water Tagging}

[76] The goal is to quantify the isotopic effect of continental recycling, downdraft recycling, and precipitation reevaporation using water-tagging experiments. This applies for experiments in which we tag the continental evaporation versus the rest (experiment 2), unsaturated downdrafts versus the rest (experiment 4 ), and precipitation reevaporation versus the rest (experiment 5).

[77] Considering the water vapor as a mixture of two water reservoirs, the isotopic variations can be caused by isotopic variations in either one of the mixing components or by changes in the mixing proportions. Taking the example of experiment 4 , we have

$$
\delta_{v}=r_{\mathrm{dft}} \delta_{\mathrm{dft}}+\left(1-r_{\mathrm{dft}}\right) \delta_{\text {rest }},
$$

where $\delta_{v}, \delta_{\mathrm{dft}}$, and $\delta_{\text {rest }}$ are the $\delta$ of the total vapor, unsaturated downdraft vapor, and the remaining vapor and $r_{\mathrm{dft}}$ is the proportion of the total vapor originating from unsaturated downdrafts.

[78] Differentiating and linearizing this equation yields

$$
d \delta_{v}=d r_{\mathrm{dft}} \overline{\left(\delta_{\mathrm{dft}}-\delta_{\mathrm{rest}}\right)}+\overline{r_{\mathrm{dft}}} d\left(\delta_{\mathrm{dft}}-\delta_{\text {rest }}\right)+d \delta_{\text {rest }},
$$

where $d$ indicates the difference from the temporal average and the overline indicates temporal average. The three terms represent respectively (1) change in the proportion of vapor from unsaturated downdrafts, (2) change in downdrafts composition relatively to the remaining water, and (3) isotopic variations in the remaining water. Their sum should equal $d \delta_{v}$ within errors related to neglecting nonlinear terms. We chose to isolate $d\left(\delta_{\mathrm{dft}}-\delta_{\text {rest }}\right)$ rather than $d \delta_{\mathrm{dft}}$ so processes 
unrelated to unsaturated downdrafts affecting all water vapor parcels will be excluded from the unsaturated downdraft term (term 2). We quantify these contributions to $\delta_{v}$ variability by applying the method explained in Appendix B.

\section{Appendix D: Quantifying Continental Recycling From Isotope Measurements}

[79] The isotope composition of the vapor $\delta_{v}$ results from a mixture of vapor from continental and oceanic origins as follows:

$$
\delta_{v}=\left(1-r_{\text {con }}\right) \delta_{\text {voce }}+r_{\text {con }} \delta_{\text {vcon }},
$$

where $r_{\text {con }}$ is the proportion of the vapor originating from continental evaporation and $\delta_{\text {voce }}$ and $\delta_{\text {vcon }}$ are the $\delta$ of the vapor originating from ocean and continental evaporation respectively.

[80] We assume that the continental vapor originates from the precipitation that has accumulated in the soil as follows:

$$
\delta_{\mathrm{vcon}}=\delta_{p},
$$

and that the disequilibrium between precipitation and vapor is constant

$$
\epsilon=\delta_{p}-\delta_{v}
$$

[81] Then

$$
\delta_{v}=\delta_{\mathrm{voce}}+\frac{r_{\mathrm{con}}}{1-r_{\mathrm{con}}} \epsilon
$$

[82] By differentiating along a trajectory, we get

$$
d\left(\frac{r_{\mathrm{con}}}{1-r_{\mathrm{con}}}\right) / d x=\frac{d \delta_{v} / d x-d \delta_{\mathrm{voce}} / d x}{\delta_{p}-\delta_{v}}
$$

[83] Acknowledgments. We gratefully thank Luc Descroix, Boubacar Ibrahim, Eric Lebreton, and Ibrahim Mamadou for the rain sampling in the Niamey region; S. Falourd and B. Minster for helping with the isotopic measurements. Based on a French initiative, AMMA was built by an international scientific group and is currently funded by a large number of agencies, especially from France, the United Kingdom, the United States and Africa. It has been the beneficiary of a major financial contribution from the European Community's Sixth Framework Research Programme. Detailed information on scientific coordination and funding is available on the AMMA International web site http://www.amma-international.org. This work was funded by the IPSL project, AMMA API and LEFE/MISTERRE national programme. We thank three anonymous reviewers for their constructive comments.

\section{References}

Allison, G. B., C. J. Barnes, and M. W. Hughes (1983), The distribution of deuterium and oxygen 18 in dry soils. II. Experimental, J. Hydrol., 64, 377-397.

Araguas-Araguas, L., K. Froehlich, and K. Rozanski (1998), Stable isotope composition of precipitation over southeast Asia, J. Geophy. Res., 103(D22), 28,721-28,742.

Barnes, C., and G. Allison (1988), Tracing of water movement in the unsaturated zone using stable isotopes of hydrogen and oxygen, J. Hydrol, $100,143-176$.
Barnes, C. J., and G. B. Allison (1983), The distribution of deuterium and oxygen 18 in dry soils: I. Theory, J. Hydrol., 60, 141-156.

Bony, S., C. Risi, and F. Vimeux (2008), Influence of convective processes on the isotopic composition $(\delta \mathrm{O} 18$ and $\delta \mathrm{D})$ of precipitation and water vapor in the Tropics. Part 1: Radiative-convective equilibrium and TOGA-COARE simulations, J. Geophys. Res., 113, D19305, doi:10.1029/2008JD009942.

Bosilovich, M. G., and S. D. Schubert (2002) Water vapor tracers as diagnostics of the regional hydrologic cycle, J. Hydrometeor., 3, 149-165.

Brown, D., J. Worden, and D. Noone (2008), Comparison of atmospheric hydrology over convective continental regions using water vapor isotope measurements from space, J. Geophys. Res., 113, D15124, doi:10.1029/ 2007JD009676.

Chepfer, H., S. Bony, D. Winker, M. Chiriaco, J.-L. Dufresne, and G. Sèze (2008) Use of CALIPSO lidar observations to evaluate the cloudiness simulated by a climate model, Geophys. Res. Lett., 35, L15704, doi:10.1029/2008GL034207.

Cole, J. E., D. Rind, R. S. Webb, J. Jouzel, and R. Healy (1999), Climatic controls on interannual variability of precipitation delta180: Simulated influence of temperature, precipitation amount, and vapor source region, J. Geophys. Res., 104, 14,223-14,236.

Cook, K. H., and E. K. Vizy (2006), Coupled model simulations of the West African monsoon system: Twentieth- and twenty-first-century simulations, J. Clim., 19, 3681-3703.

Couhert, A., T. Schneider, J. Li, D. E. Waliser, and A. M. Tompkins (2010), The maintenance of the relative humidity of the subtropical free troposphere, J. Clim., 23(2), 390-403.

Cuesta, J., et al. (2008), Multiplatform observations of the seasonal evolution of the Saharan atmospheric boundary layer in Tamanrasset, Algeria, in the framework of the African Monsoon Multidisciplinary Analysis field campaign conducted in 2006, J. Geophys. Res., 113, D00C07, doi:10.1029/2007JD009417.

Dansgard, W. (1964), Stable isotopes in precipitation, Tellus, 16, 436-468.

Delaygue, G., V. Masson, J. Jouzel, R. D. Koster, and R. J. Healy (2000), The origin of Antarctic precipitation: A modelling approach, Tellus, Ser. B, 52, 19-36.

Dessler, A. E., and S. C. Sherwood (2003), A model of HDO in the tropical tropopause layer, Atmos. Chem. Phys., 3, 2173-2181.

Ducoudré, N., K. Laval, and A. Perrier (1993), SECHIBA, a new set of parametrizations of the hydrological exchanges at the land-atmosphere interface within the LMD atmospheric general circulation model, J. Clim., 6, 248-273.

Emanuel, K. A. (1991), A scheme for representing cumulus convection in large-scale models., J. Atmos. Sci., 48, 2313-2329.

Emanuel, K. A., and R. T. Pierrehumbert (1996), Microphysical and dynamical control of tropospheric water vapor, in NATO ASI Ser., Ser. I, edited by P. J. Crutzen and V. Ramanathan, vol. 135, pp. 17-28.

Emanuel, K. A., and M. Zivkovic-Rothman (1999), Development and evaluation of a convection scheme for use in climate models, J. Atmos. Sci., 56, 1766-1782.

Field, R. D., D. B. A. Jones, and D. P. Brown (2010), Effects of postcondensation exchange on the isotopic composition of water in the atmosphere, J. Geophys. Res., doi:10.1029/2010JD014334, in press.

Fontaine, B., and S. Janicot (1996), Sea surface temperature fields associated with West African rainfall anomaly types, J. Clim., 9, 2935-2940.

Frankenberg, C., et al. (2009), Dynamic processes governing lowertropospheric $\mathrm{HDO} / \mathrm{H}_{2} \mathrm{O}$ ratios as observed from space and ground, Science, 325, 1374-1377.

Galewsky, J., and J. V. Hurley (2010), An advection-condensation model for subtropical water vapor isotopic ratios, J. Geophys. Res., 115 , D16116, doi:10.1029/2009JD013651.

Galewsky, J., A. Sobel, and I. Held (2005), Diagnosis of subtropical humidity dynamics using tracers of last saturation, J. Atmos. Sci., 62(9), 3353-3367.

Galewsky, J., M. Strong, and Z. D. Sharp (2007), Measurements of water vapor $\mathrm{d} / \mathrm{h}$ ratios from Mauna Kea, Hawaii, and implications for subtropical humidity dynamics, Geophys. Res. Lett., 34, L22808, doi:10.1029/ 2007GL031330.

Gat, J. R., and E. Matsui (1991), Atmospheric water balance in the Amazon basin: An isotopic evapotranspiration model, J. Geophys. Res., 96(D7), 13,179-13,188.

Gates, W. L. (1992), AMIP: The Atmospheric Model Intercomparison Project, Bull. Am. Meteorol. Soc., 73, 1962-1970.

Godunov, S. K. (1959), Finite-difference methods for the numerical computations of equations of gas dynamics, Math. Sb., 7, 271-290.

Grandpeix, J.-Y., and J.-P. Lafore (2010), A density current parameterization coupled with Emanuel's convection scheme. Part I: The models, J. Atmos. Sci., 67, 881-897. 
Grandpeix, J.-Y., J.-P. Lafore, and F. Cheruy (2010), A density current parameterization coupled with Emanuel's convection scheme. Part II: 1D simulations, J. Atmos. Sci., 67, 898-922.

Gupta, P., D. Noone, J. Galewsky, C. Sweeney, and B. H. Vaughn (2009), Demonstration of high-precision continuous measurements of water vapor isotopologues in laboratory and remote field deployments using wavelength-scanned cavity ring-down spectroscopy (WS-CRDS) technology, Rapid Commun. Mass Sp., 23, 2534-2542.

Hall, N., and P. Peyrillé (2006), Dynamics of the West African monsoon, J. Phys. IV, 139, 81-99.

Haynes, J. M., R. T. Marchand, Z. Luo, A. Bodas-Salcedo, and G. L. Stephens (2007), A multipurpose radar simulation package: QuickBeam, Bull. Am. Meteorol. Soc., 88, 1723-1727, doi:10.1175/BAMS-88-11-1723.

Herbin, H., D. Hurtmans, C. Clerbaux, L. Clarisse, and P.-F. Coheur (2009), $\mathrm{H}_{2}^{16} \mathrm{O}$ and HDO measurements with IASI/MetOp, Atmos. Chem. Phys. Discuss., 9, 9267-9290.

Hoffmann, G., M. Werner, and M. Heimann (1998), Water isotope module of the ECHAM atmospheric general circulation model: A study on timescales from days to several years, J. Geophys. Res., 103(D14), 16,871-16,896.

Hourdin, F., and A. Armengaud (1999), The use of finite-volume methods for atmospheric advection of trace species. Part I: Test of various formulations in a general circulation model, Mon. Wea. Rev., 127, 822-837.

Hourdin, F., F. Couvreux, and L. Menut (2002), Parameterization of the dry convective boundary layer based on a mass flux representation of thermals, J. Atmos. Sci., 59(6), 1105-1123.

Hourdin, F., et al. (2006), The LMDZ4 general circulation model: Climate performance and sensitivity to parametrized physics with emphasis on tropical convection, Clim. Dyn., 27, 787-813.

Huffman, G. J., P. Arkin, and J. Janowiak (1997), The Global Precipitation Climatology Project (GPCP) combined precipitation dataset, Bull. Am. Meteorol. Soc., 78, 5-20.

Hurley, J. V., and J. Galewsky (2010), A last saturation diagnosis of subtropical water vapor response to global warming, Geophys. Res. Lett., 37, L06702, doi:10.1029/2009GL042316.

Janicot, S., et al. (2008), Large-scale overview of the summer monsoon over West and Central Africa during the AMMA field experiment in 2006, Ann. Geophys., 26, 2569-2595.

John, V. O., and B. J. Soden (2007), Temperature and humidity biases in global climate models and their impact on climate feedbacks, Geophys. Res. Lett., 34, L18704, doi:10.1029/2007GL030429.

Joussaume, S., J. Jouzel, and R. Sadourny (1984), A general circulation model of water isotope cycles in the atmosphere, Nature, 311, 24-29.

Kalnay, E., et al. (1996), The NCEP/NCAR 40-year reanalysis project, Bull. Am. Meteorol. Soc., 77, 437-470.

Klein, S. A., and C. Jakob (1999), Validation and sensitivities of frontal clouds simulated by the ECMWF model, Mon. Weather Rev., 127, 2514-2531.

Koster, R., J. Jouzel, R. Suozzo, G. Russell, W. Broecker, D. Rind, and P. Eagleson (1986), Global sources of local precipitation as determined by the NASA/GISS GCM, Geophys. Res. Lett., 13(2), 121-124, doi:10.1029/GL013i002p00121.

Koster, R. D., J. Jouzel, R. J. Suozzo, and G. L. Russell (1992), Origin of July Antarctic precipitation and its influence on deuterium content: A GCM analysis, Clim. Dyn., 7, 195-203.

Krinner, G., C. Genthon, Z.-X. Li, and P. L. Van (1997), Studies of the Antarctic climate with a stretched-grid general circulation model, J. Geophys. Res., 102, 13,731-13,745.

Krinner, G., N. Viovy, N. de Noblet-Ducoudre, J. Ogee, J. Polcher, P. Friedlingstein, P. Ciais, S. Sitch, and I. C. Prentice (2005), A dynamic global vegetation model for studies of the coupled atmosphere-biosphere system, Global Biogeochem. Cycles, 19, GB1015, doi:10.1029/ 2003GB002199.

Lawrence, J. R., and S. D. Gedzelman (1996), Low stable isotope ratios of tropical cyclone rains, Geophys. Res. Lett., 23, 527-530.

Lawrence, J. R., S. D. Gedzelman, D. Dexheimer, H.-K. Cho, G. D. Carrie, R. Gasparini, C. R. Anderson, K. P. Bowman, and M. I. Biggerstaff (2004), Stable isotopic composition of water vapor in the tropics, J. Geophys. Res., 109, D06115, doi:10.1029/2003JD004046.

Le Barbé, L., T. Lebel, and D. Tapsoba (2002), Rainfall variability in West Africa during the years 1950-90, J. Clim., 15, 187-202.

Lee, J., J. Worden, D. Noone, J. Adkins, K. Bowman, A. Elering, A. LeGrande, J.-L. Li, and G. Schmidt (2010), Relating tropical ocean clouds to moist processes using water vapor isotope measurements, Atmos. Chem. Phys. Discuss., in preparation.

Lee, J.-E., and I. Fung (2008), “Amount effect" of water isotopes and quantitative analysis of post-condensation processes, Hydrol. Processes, 22(1), $1-8$
Lee, J.-E., R. Pierrehumbert, A. Swann, and B. R. Lintner (2009), Sensitivity of stable water isotopic values to convective parameterization schemes, Geophys. Res. Lett., 36, L23801, doi:10.1029/2009GL040880.

Marti, O., et al. (2005), The New IPSL Climate System Model, Tech. Rep. IPSL-CM4, IPSL.

Matthews, A. J. (2004), Intraseasonal variability over tropical Africa during northern summer, J. Clim., 17, 2428-2440.

Meehl, G. A., K. Covey, T. Delworth, M. Latif, B. McAvaney, J. F. B. Mitchell, R. J. Stouffer, and K. Taylor (2007), The WCRP CMIP3 multimodel dataset: A new era in climate change research, Bull. Am. Meteorol. Soc., 7, 1383-1394.

Moreira, M., L. Sternberg, L. Martinelli, R. Victoria, E. Barbosa, C. Bonates, and D. Nepstad (1997), Contribution of transpiration to forest ambient vapor based on isotopic measurements, Global Change Biol., 3, 439-450.

Mounier, F., and S. Janicot (2004), Evidence of two independent modes of convection at intraseasonal timescale in the West African summer monsoon, Geophys. Res. Lett., 31, L16116, doi:10.1029/2004GL020665.

Moyer, E. J., F. W. Irion, Y. L. Yung, and M. R. Gunson (1996), ATMOS stratospheric deuterated water and implications for tropospherestratosphere transport, Geophys. Res. Lett., 23(17), 2385-2388.

New, M., M. Hulme, and P. Jones (1999), Representing twentieth century space-time climate variability. Part I: Development of a 1961-1990 mean monthly terrestrial climatology, J. Clim., 12, 829-856.

Nicholson, S. E. (1981), The nature of rainfall fluctuations in subtropical West Africa, Mon. Weather Rev., 108, 473-487.

Nicholson, S. E. (2000), Land surface processes and Sahel climate, Rev. Geophys., 38, 117-139.

Noone, D. (2008), The influence of midlatitude and tropical overturning circulation on the isotopic composition of atmospheric water vapor and Antarctic precipitation, J. Geophys. Res., 113, D04102, doi:10.1029/ 2007JD008892.

Noone, D., and I. Simmonds (2002a), Associations between $\delta^{18} \mathrm{O}$ of water and climate parameters in a simulation of atmospheric circulation for 1979-95, J. Clim., 15, 3150-3169.

Noone, D., and I. Simmonds (2002b), Annular variations in moisture transport mechanisms and the abundance of $\delta \mathrm{O} 18$ in Antarctic snow, J. Geophys. Res., 107(D24), 4742, doi:10.1029/2002JD002262.

Nuret, M., J.-P. Lafore, F. Guichard, J.-L. Redelsperger, O. Bock, A. Augusti-Panareda, and J.-B. N'Gamini (2008), Correction of humidity bias for Vaisala RS80-A sondes during the AMMA 2006 observing period, J. Atmos. Oceanic Technol., 25, 2152-2158.

Pierce, D. W., T. P. Barnett, E. J. Fetzer, and P. J. Gleckler (2006), Threedimensional tropospheric water vapor in coupled climate models compared with observations from the AIRS satellite system, Geophys. Res. Lett., 33, L21701, doi:10.1029/2006GL027060.

Pierrehumbert, R. T., and R. Roca (1998), Evidence for control of Atlantic subtropical humidity by large scale advection, Geophys. Res. Lett., 25 (24), 4537-4540.

Redelsperger, J.-L., C. Thorncroft, D. Arona, T. Lebel, D. Parker, and J. Polcher (2006), African monsoon multidisciplinary analysis: An international research project and field campaign, Bull. Am. Meteorol. Soc., 87, 1739-1746.

Rio, C., and F. Hourdin (2007), A thermal plume model for the convective boundary layer: Representation of cumulus clouds, J. Atmos. Sci., 65, $407-425$.

Rio, C., F. Hourdin, J.-Y. Grandpeix, and J.-P. Lafore (2009), Shifting the diurnal cycle of parameterized deep convection over land, Geophys. Res. Lett., 36, L07809, doi:10.1029/2008GL036779.

Risi, C., S. Bony, and F. Vimeux (2008a), Influence of convective processes on the isotopic composition (O18 and D) of precipitation and water vapor in the Tropics. Part 2: Physical interpretation of the amount effect, J. Geophys. Res., 113, D19306, doi:10.1029/2008JD009943.

Risi, C., S. Bony, F. Vimeux, L. Descroix, B. Ibrahim, E. Lebreton, I. Mamadou, and B. Sultan (2008b), What controls the isotopic composition of the African monsoon precipitation? Insights from event-based precipitation collected during the 2006 AMMA campaign, Geophys. Res. Lett., 35, L24808, doi:10.1029/2008GL035920.

Risi, C., S. Bony, F. Vimeux, M. Chong, and L. Descroix (2010a), Evolution of the water stable isotopic composition of the rain sampled along Sahelian squall lines, Q. J. R. Meteorol. Soc., 136(S1), 227-242.

Risi, C., S. Bony, F. Vimeux, and J. Jouzel (2010b), Water stable isotopes in the LMDZ4 General Circulation Model: model evaluation for present day and past climates and applications to climatic interpretation of tropical isotopic records, J. Geophys. Res., 115, D12118, doi:10.1029/2009JD013255.

Roca, R., L. Picon, M. Desbois, H. Le Treut, and J.-J. Morcrette (1997), Direct comparison of Meteosat water vapor channel data and general circulation model results, Geophys. Res. Lett., 24(2), 147-150. 
Roca, R., J.-P. Lafore, C. Piriou, and J.-L. Redelsperger (2005), Extratropical dry-air intrusions into the West African monsoon midtroposphere: An important factor for the convective activity over the Sahel, J. Atmos. Sci., 62, 390-407.

Rozanski, K., L. Araguas-Araguas, and R. Gonfiantini (1993), Isotopic patterns in modern global precipitation, in Climate Change in Continental Isotopic Records, Geophys. Monogr. Ser., AGU, Washington, D. C.

Schneider, T., K. L. Smith, P. A. O'Gorman, and C. C. Walker (2006), A climatology of tropospheric zonal-mean water vapor fields and fluxes in isentropic coordinates, J. Clim., 19(22), 5918-5933.

Sherwood, S. C. (1996), Maintenance of the free tropospheric tropical water vapor distribution. part II: simulation of large-scale advection, J. Clim., 11, 2919-2934.

Sherwood, S., and C. Meyer (2006), The general circulation and robust relative humidity, J. Clim., 19(24), 6278-6290.

Sherwood, S., R. Roca, T. M. Weckwerth, and N. G. Andronova (2010a), Tropospheric water vapor, convection, and climate, Rev. Geophys., 48, RG2001, doi:10.1029/2009RG000301.

Sherwood, S. C., W. Ingram, Y. Tsushima, M. Satoh, P. L. V. M. Roberts, and P. A. O'Gorman (2010b), Relative humidity changes in a warmer climate, J. Geophys. Res., 115, D09104, doi:10.1029/2009JD012585.

Spencer, R. W., and W. D. Braswell (1997), How dry is the tropical free troposphere? implications for global warming theory, Bull. Am. Meteorol. Soc., 78(6), 1097-1106.

Stewart, M. K. (1975), Stable isotope fractionation due to evaporation and isotopic exchange of falling waterdrops: Applications to atmospheric processes and evaporation of lakes, J. Geophys. Res., 80(9), 1133-1146.

Sultan, B., S. Janicot, and A. Diedhiou (2003), The West African monsoon dynamics. Part I: Documentation of intraseasonal variability, J. Clim., 16, 3389-3406.

Sultan, B., C. Baron, M. Dingkuhn, B. Sarr, and S. Janicot (2005), Agricultural impacts of large-scale variability of the West African monsoon, Agr. For. Meteorol., 128(1-2), 93-110.

Taylor, C. M., E. F. Lambin, N. Stephenne, R. J. Harding, and R. L. Essery (2002), The influence of land use change on climate in the Sahel, J. Clim., 15, 3615-3629.

Uppala, S., et al. (2005), The ERA-40 re-analysis, Q. J. R. Meteorol. Soc., $131,2961-3012$.

Van Leer, B. (1977), Towards the ultimate conservative difference scheme. IV. A new approach to numerical convection, J. Comput. Phys., 23, 276-299.

Vuille, M., R. S. Bradley, M. Werner, R. Healy, and F. Keimig (2003), Modeling $\delta^{18} \mathrm{O}$ in precipitation over the tropical Americas. 1. Interannual variability and climatic controls, J. Geophys. Res., 108(D6), 4174, doi:10.1029/2001JD002038.

Washburn, E., and E. Smith (1934), The isotopie fractionation of water by physiological processes, Science, 79, 188-189.
Webb, M., C. Senior, S. Bony, and J. J. Morcrette (2001), Combining ERBE and ISCCP data to assess clouds in the Hadley Centre, ECMWF and LMD atmospheric, Clim. Dyn., 17, 905-922.

Webster, C. R., and A. J. Heymsfield (2003), Water isotope ratios D/H, 18O/ $16 \mathrm{O}, 17 \mathrm{O} / 16 \mathrm{O}$ in and out of clouds map dehydration pathways, Science, $302,1742-1746$.

Werner, M., M. Heimann, and G. Hoffmann (2001), Isotopic composition and origin of polar precipitation in present and glacial climate simulations, Tellus, Ser. B, 53, 53-71.

Worden, J., D. Noone, and K. Bowman (2007), Importance of rain evaporation and continental convection in the tropical water cycle, Nature, 445, 528-532.

Worden, J., et al. (2006), Tropospheric Emission Spectrometer observations of the tropospheric $\mathrm{HDO} / \mathrm{H}_{2} \mathrm{O}$ ratio: Estimation approach and characterization, J. Geophys. Res., 111, D16309, doi:10.1029/2005JD006606.

Worden, J., et al. (2010), Comparison of TES satellite and in situ $\mathrm{HDO} / \mathrm{H}_{2} \mathrm{O}$ measurements over Mauna Loa, in preparation.

Wright, J. S., A. H. Sobel, and G. A. Schmidt (2009), The influence of condensate evaporation on water vapor and its stable isotopes in a GCM, Geophys. Res. Lett., L12804, doi:10.1029/2009GL038091.

Wright, J. S., A. Sobel, and J. Galewsky (2010), Diagnosis of zonal mean relative humidity changes in a warmer climate, J. Clim., in press.

Xie, P., and P. Arkin (1997), Global precipitation: A 17-year monthly analysis based on gauge observations, satellite estimates, and numerical model outputs, Bull. Am. Meteorol. Soc., 78, 2539-2558.

Yoshimura, K., T. Oki, N. Ohte, and S. Kanae (2004), Colored moisture analysis estimates of variations in 1998 Asian monsoon water sources, J. Meteorol. Soc. Jpn., 82, 1315-1329.

Yoshimura, K., M. Kanamitsu, and M. Dettinger (2010), Regional downscaling for stable water isotopes: A case study of an atmospheric river event, J. Geophys. Res., 115, D18114, doi:10.1029/2010JD014032.

Yu, W., M. Doutriaux, G. Sèze, H. L. Treut, and M. Desbois (1996), A methodology study of the validation of clouds in GCMs using ISCCP satellite observations, Clim. Dyn., 12(6), 389-401.

Zeng, N., J. D. Neelin, K.-M. Lau, and C. J. Tucker (1999), Enhancement of interdecadal climate variability in the sahel by vegetation interaction, Science, 286, 1537, doi:10.1126/science.286.5444.1537.

S. Bony, Laboratoire de Météorologie Dynamique, Case postale 99, 4, Place Jussieu, 75252 Paris cedex 05, France.

C. Frankenberg and J. Worden, Jet Propulsion Laboratory, California Institute of Technology, 4800 Oak Grove Dr., Pasadena, CA 91109, USA.

D. Noone and C. Risi, Cooperative Institute for Research in Environmental Sciences, University of Colorado at Boulder, Building 318, 216 UCB, Boulder, CO 80309, USA. (camille.risi@1md.jussieu.fr) F. Vimeux, Laboratoire des Sciences du Climat et de l'Environnement, Bat 701, Orme des Merisiers, 91191 Gif-sur-Yvette, France. 